Disponível em:

http://editora.unoesc.edu.br/index.php/race

RACE, Joaçaba, v. 17, n. 1, p. 245-282, jan./abr. 2018

\title{
NOTÍCIAS DO MERCADO DE CAPITAIS E JANELAS DE EVENTOS PARA ADESÕES E MIGRAÇÕES AOS NDGCS
}

Capital market news and windows of events for accessions and migrations to NDGCs

\author{
Ricardo Adriano Antonelli \\ E-mail: rantonelli@utfpr.edu.br
}

Mestre em Contabilidade e Finanças pela Universidade Federal do Paraná; Doutorando em Contabilidade no Programa de Pós-Graduação em Contabilidade da Universidade Federal do Paraná; Perito Judicial há mais de cinco anos de atuação em causas cíveis. Endereço para contato: Via do Conhecimento, Km 1, 85503-390, Pato Branco, Paraná, Brasil.

Ademir Clemente

E-mail: ademir@ufpr.br Pós-doutor pela COPPE/Universidade Federal do Rio de Janeiro e pela University of London; Doutor em Engenharia de Transportes pela Universidade Federal do Rio de Janeiro; Vice-Diretor do Setor de Ciências Sociais Aplicadas da Universidade Federal do Paraná.

\section{Romualdo Douglas Colauto}

E-mail: rdcolauto.ufpr@gmail.com

Pós-doutor em Controladoria e Contabilidade pela Universidade de São Paulo; Doutor em Engenharia de Produção na Área de Gestão de Negócios pela Universidade Federal de Santa Catarina; Coordenador do Programa de Pós-Graduação em Contabilidade - Mestrado e Doutorado - da Universidade Federal do Paraná.

Artigo recebido em 01 de dezembro de 2016. Aceito em 06 de dezembro de 2017. 


\section{Resumo}

Neste artigo teve-se como objetivo analisar a influência das notícias relacionadas ao mercado de capitais na determinação da janela do evento para adesões e migrações aos Níveis Diferenciados de Governança Corporativa (NDGCs) da $B^{3 \text { (Brasil, Bolsa, Balcão) }}$. A metodologia emprega quatro etapas: determinação do melhor tamanho da janela para 104 empresas; análise do tamanho das janelas consideradas outliers; análise qualitativa das notícias referentes à janela do evento para os outliers, com base no Bloomberg®; e aplicação do Estudo de Eventos para os casos considerados outliers. Os resultados encontrados indicaram uma tendência de pequenas janelas, limitadas a 5-5 dias para cerca de 59,6\% dos casos. Para os 42 casos considerados outliers, isto é, janela maior que 5-5 dias, foram encontradas notícias para 61,9\%, dos quais apenas 6 casos apresentaram dummies significativas no Estudo de Eventos. A metodologia utilizada conseguiu explicar 68 casos em que houve adesão, migração ou notícia.

Palavras-chave: Governança Corporativa. Estudo de eventos. Janelas de eventos. Notícias.

\section{Abstract}

This article aims to analyze the influence of news related to the capital market in determining the window of the event for accessions and migrations to the BM\&FBovespa NDGCs. Four steps are followed: determinig the best size of the window for 104 companies; analysing the size of the Windows which are considered outliers; qualitative analysis of the news related to the window of events for outliers, based on Bloomberg ${ }^{\circledR}$; and application of the Event Studies for the cases considered outliers. The results of the study indicated a tendency of small windows, limited to 5-5 days for about 59.6\% of the cases. For the 42 cases considered outliers, i.e, window bigger than 5-5 days, news was found for $61.9 \%$, from which just 6 ones got meaningful dummies in the Event Study. Even though, the applied methodology succeded explaining 68 of the cases in which there was accession, migration or news.

Keywords: Corporate Governance. Windows of Events. Janelas de eventos. News.

\section{INTRODUÇÃO}

A Governança Corporativa (GC) é um tema que ganhou destaque nos últimos anos no mercado de capitais brasileiro. Alguns dos fatores responsáveis pela crescente importância do tema são: a necessidade de atrair capital e fontes de financiamento por parte das organizações; os benefícios advindos da maior transparência na gestão empresarial; e a importância dos relacionamentos entre acionistas, cotistas e demais conselhos das empresas (RODRIGUES et al., 2015). 
No contexto internacional diversas iniciativas sinalizam os princípios e práticas recomendadas de Governança Corporativa do Relatório Cadbury, trabalho realizado por um Comitê do Banco da Inglaterra com o objetivo de elaborar um Código de Melhores Práticas de Governança Corporativa (CADBURY, 1992). Posteriormente, em 2004, a Organisation for Economic Co-Operation and Development (OECD) publicou os Principles of Corporate Governance, nos quais foi desenvolvido um conjunto de normas e diretrizes aplicadas à Governança Corporativa. Tais publicações ainda são consideradas referências na adoção de boas práticas de Governança Corporativa no Brasil, por parte da Comissão de Valores Mobiliários (CVM), do Instituto

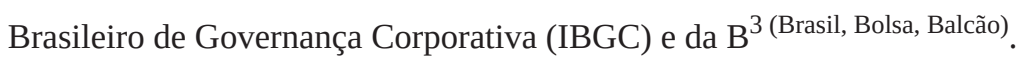

No ano 2000, a B ${ }^{3}$ (Brasil, Bolsa, Balcão) , com o objetivo de proporcionar um ambiente de negociação que estimulasse o interesse dos investidores e a valorização das companhias, criou os Níveis Diferenciados de Governança Corporativa (NDGCs), classificando as empresas em Nível 1 (N1), Nível 2 (N2), Novo Mercado (NM) e mercado tradicional. Em 2005, adicionou a esses segmentos a Bovespa Mais.

Os NDGCs funcionam como uma espécie de selo de qualidade, cujo valor reside nas obrigações contratuais assumidas pela empresa e na maneira como a $\mathrm{B}^{3 \text { (Brasil, }}$ Bolsa, Balcão) administra seus contratos (CARVALHO, 2002). Nesse sentido, os estudos de Carvalho (2002), Nishi (2003), Leal e Carvalhal-da-Silva (2004), Leal e Carvalhal-da-Silva (2005), Nakayasu (2006), Sirqueira e Kalatzis (2006), Souza e Marcon (2006), Colombo e Galli (2010), Catapan e Colauto (2014), Clemente et al. (2014), Marques et al. (2015), Vilhena e Camargos (2015) e Silva e Martins (2015) buscaram comprovar a efetividade das práticas de Governança Corporativa sobre o desempenho e a valorização acionária. Por outro lado, Comerlato, Terra e Braga (2002), Batistella et al. (2014), Costa e Camargos (2006), Camargos e Barbosa (2006), Pires (2006), Neves e Lemes (2009), Santos et al. (2013), Bernardinho, Peixoto e Ferreira (2014), Carlesso Neto (2014) e Rodrigues et al. (2015) não obtiveram evidências confirmatórias de que as boas práticas de Governança Corporativa se refletem em valorização acionária.

A maior parte desses trabalhos utiliza como metodologia do Estudo de Eventos, inspirados na pesquisa de Dolley (1933), em que o autor analisou os efeitos nos preços em dias próximos da divulgação de 95 desdobramentos de ações no período de 1921 a 1931. Após o estudo de Dolley (1933), a metodologia do Estudo de Eventos passou por uma série de aperfeiçoamentos, destacando-se as contribuições de Ball e Brown (1968) e Fama et al. (1969) (MACKINLAY, 1997). 
Na operacionalização do Estudo de Eventos há uma convergência quanto à posição da janela do evento. Entretanto, isso não ocorre quanto aos tamanhos das janelas. As maiores discrepâncias foram constatadas nos estudos de Carvalho (2002), que utilizou janelas de três dias, e de Camargos e Barbosa (2006), que empregaram janelas de 504 dias.

Sabe-se que o tamanho da janela do evento é um dos pontos mais subjetivos e cruciais da metodologia do Estudo de Eventos. Camargos e Barbosa (2003, 2010) expõem que o tamanho da janela envolve um certo grau de subjetividade e arbitrariedade, uma vez que a literatura apenas sugere que a janela do evento deve ser grande o suficiente para contemplar momentos considerados importantes, mas não muito extensa a ponto de provocar interferências de outros fatores.

Silva, Carvalho e Nunes (2012) citam que o mercado de ações é movido por informações, quantitativas ou qualitativas, relativas às companhias negociadas e aos agregados setoriais e macroeconômicos. Tais informações, geralmente em forma de notícias, vinculadas ao mercado de ações, tendem a influenciar o comportamento do mercado, e indiretamente, a valorização acionária. O efeito de notícias do mercado de capitais foi estudado por Cutler, Porteba e Summers (1989), para quem a variação do mercado acionário é reflexo das notícias no mundo financeiro e econômico.

Não obstante, a metodologia do Estudo de Eventos deve ser empegada com cautela, pois além da subjetividade inerente à escolha do tamanho da janela de evento, também devem ser analisados outros eventos que possam estar influenciando os resultados oriundos da referida metodologia. Diante do exposto, a questão orientadora deste artigo é: qual a influência das notícias vinculadas ao mercado de capitais na determinação da janela do evento para adesões e migrações aos NDGCs da B ${ }^{3}$ (Brasil, Bolsa, Balcão)?

Considerando a questão de pesquisa, o objetivo foi analisar a influência das notícias vinculadas ao mercado de capitais na determinação da janela do evento para adesões e migrações aos NDGCs da $B^{3 \text { (Brasil, Bolsa, Balcão) }}$. Sob o ponto de vista operacional, para casos que mostrem tamanhos de janelas de eventos diferentes da maioria dos elementos da amostra, serão analisadas as notícias divulgadas ao mercado de capitais a fim de entender como tais notícias influenciaram a flutuação da valorização acionária.

Espera-se que os resultados possam proporcionar subsídios para melhor compreender os aspectos metodológicos envolvidos em Estudo de Eventos. Acredita-se que tais benefícios possam ser utilizados não apenas para as pesquisas relacionadas 
às práticas de Governança Corporativa e valorização das empresas, mas para todas as pesquisas que empregam a referida metodologia nas diversas áreas do conhecimento. Para os investidores, os achados poderão ajudar a informar sobre o comportamento do valor das ações em decorrência do resultado de práticas de Governança Corporativa, e, ainda, facilitar o entendimento da reação do mercado a notícias divulgadas. No contexto organizacional, o estudo é importante porque contribui para entender o comportamento do mercado em relação aos seus esforços na adoção de práticas de governança e de notícias vinculadas, as quais, de certa forma, resumem-se no valor das ações no mercado.

\section{GOVERNANÇA CORPORATIVA E ESTUDOS DE EVENTOS}

O surgimento da Sociedade Anônima com capital fragmentado em ações é considerado um fenômeno que contribuiu para os estudos de Governança Corporativa. Nesse ambiente corporativo, o sistema acionário tem grande importância aos stakeholders, motivado pela separação da propriedade e controle. Além disso, o sistema acionário é considerado o principal fator de organização econômica em razão da sua capacidade de mobilizar os interesses da propriedade (BERLE, MEANS, 1984; RODRIGUES et al., 2015). Nesse ambiente, os estudos de Governança Corporativa iniciaram com Coase (1937), Jensen e Meckling (1976) e Williamson (1991), que apesar de não utilizarem o termo Governança Corporativa, desenvolveram na Teoria da Firma todo o arcabouço teórico essencial para o entendimento de aspectos que envolvem a Governança Corporativa.

Esses estudos foram e são importantes referenciais nas pesquisas relacionadas ao tema Governança Corporativa, que segundo Denis e McConnel (2003) podem ser subdivididas em três gerações. A primeira geração buscou estimar o impacto de um mecanismo isolado de Governança Corporativa sobre o desempenho e a tomada de decisões. A segunda geração focou o sistema legal e de proteção ao investidor sobre as decisões corporativas e o valor das empresas. Já a terceira geração envolve a criação de índices amplos de Governança Corporativa, que consideram diferentes mecanismos, de forma integrada.

A metodologia do Estudo de Eventos nas últimas décadas vem contribuindo para as pesquisas voltadas ao mercado de capitais (CORRADO, 2011). O emprego da metodologia do Estudo de Eventos é realizado em um vasto conjunto de situações e em diversas áreas do conhecimento, nas quais, em geral, espera-se que a ocorrência de determinado evento impacte o objeto estudado durante determinado tempo. Apesar de 
todos os estudos citados empregarem a metodologia do Estudo de Eventos, observa-se que os resultados não são congruentes. Cabe destacar também que para a operacionalização de tal metodologia, é necessária a definição de três janelas: de estimação (antes), do evento (durante) e de comparação (depois). Os tamanhos dessas janelas variam amplamente nos estudos, conforme a Tabela 1 :

Tabela 1 - Tamanhos das janelas sobre Governança Corporativa

\begin{tabular}{|c|c|c|c|}
\hline Autores & Janela de Estimação & Janela do Evento & $\begin{array}{c}\text { Janela de } \\
\text { Comparação }\end{array}$ \\
\hline $\begin{array}{l}\text { Comerlato, Terra } \\
\text { e Braga (2002) }\end{array}$ & 60 pregões & $\begin{array}{l}2 \text { pregões } \\
7 \text { pregões } \\
11 \text { pregões }\end{array}$ & 30 pregões \\
\hline Carvalho (2002) & $\begin{array}{l}80 \text { pregões } \\
40 \text { pregões }\end{array}$ & $\begin{array}{l}7 \text { dias após } \\
3 \text { dias após } \\
2 \text { pregões antes e } 2 \text { depois } \\
1 \text { pregão antes e } 1 \text { depois } \\
7 \text { dias antes } \\
3 \text { dias antes }\end{array}$ & $\begin{array}{l}80 \text { pregões } \\
40 \text { pregões }\end{array}$ \\
\hline Nishi (2003) & 60 pregões & 5 antes e 20 depois (25 pregões) & Não utilizou \\
\hline $\begin{array}{l}\text { Batistella et al. } \\
\text { (2014) }\end{array}$ & 50 pregões & Vários tamanhos & Não utilizou \\
\hline $\begin{array}{l}\text { Camargos e } \\
\text { Barbosa (2006) }\end{array}$ & $\begin{array}{l}1 \text { e } 5 \text { (curtíssimo prazo) } \\
\text { 21, } 63 \text { e } 126 \text { (curto prazo) } \\
504 \text { e } 252 \text { (longo prazo) }\end{array}$ & $\begin{array}{l}1 \text { e } 5 \text { (curtíssimo prazo) } \\
21,63 \text { e } 126 \text { (curto prazo) } \\
504 \text { e } 252 \text { (longo prazo) }\end{array}$ & Não utilizou \\
\hline $\begin{array}{l}\text { Costa e Camar- } \\
\text { gos }(2006)\end{array}$ & 1, 220 e 440 dias & 1, 220 e 440 dias & Não utilizou \\
\hline $\begin{array}{l}\text { Nakayasu } \\
\text { (2006) }\end{array}$ & 50 pregões & 14 pregões & Não utilizou \\
\hline Pires (2006) & 150 dias & 150 dias & Não utilizou \\
\hline $\begin{array}{l}\text { Michalischen } \\
\text { (2008) }\end{array}$ & 90 dias & 30 dias & Não utilizou \\
\hline $\begin{array}{l}\text { Neves e Lemes } \\
\text { (2009) }\end{array}$ & 50 pregões & 14 pregões & Não utilizou \\
\hline $\begin{array}{l}\text { Camargos e } \\
\text { Barbosa (2010) }\end{array}$ & $\begin{array}{l}1 \text { a } 504 \text { pregões antes } \\
1 \text { a } 252 \text { pregões antes } \\
1 \text { a } 126 \text { pregões antes } \\
1 \text { a } 63 \text { pregões antes } \\
1 \text { a } 21 \text { pregões antes }\end{array}$ & 0 (zero) & $\begin{array}{l}1 \text { a } 504 \text { pre- } \\
\text { gões depois } \\
1 \text { a } 252 \text { pre- } \\
\text { gões depois } \\
1 \text { a } 126 \text { pre- } \\
\text { gões depois } \\
1 \text { a } 63 \text { pre- } \\
\text { gões depois } \\
1 \text { a } 21 \text { pre- } \\
\text { gões depois }\end{array}$ \\
\hline $\begin{array}{l}\text { Colombo e Galli } \\
(2010)\end{array}$ & 252 dias & 40 dias & Não utilizou \\
\hline
\end{tabular}

Fonte: os autores. 
Especificamente do mercado de capitais, com o emprego de tal metodologia, geralmente se espera que a divulgação de determinadas informações (evento) impacte as expectativas dos investidores e se reflita nos preços dos títulos. Tais situações abrangem eventos como subscrição de ações, emissão de títulos de dívida (como debêntures), lançamento de recibos de depósito em outros mercados (DRs), bonificações, pagamento de dividendos, divulgações trimestrais, semestrais ou anuais de lucros, fusões e aquisições, vencimento de opções e desdobramento de ações (splits), conforme apresentado por Camargos e Barbosa (2003).

Para Lamounier e Nogueira (2005) a metodologia do Estudo de Eventos tem como objetivo, a partir de uma hipótese de que os mercados sejam eficientes, avaliar o impacto da divulgação de uma determinada informação no valor da empresa, ou seja, mais especificamente no comportamento dinâmico dos preços e dos retornos dessa firma nos mercados financeiros. Os autores citam, ainda, que o uso da metodologia Estudos de Eventos compreende três etapas: utiliza-se um modelo de geração de retorno normal (ou esperado) do título, que é o retorno que ocorreria na ausência do evento; identifica-se o comportamento anormal nos períodos próximos ao evento de interesse; e calcula-se a diferença entre o retorno esperado e o retorno observado no período de análise. De forma mais detalhada, os procedimentos para a realização do Estudo de Eventos são apresentados por Campbell, Lo e MacKinlay (1997) em sete etapas, conforme o Quadro 1:

Quadro 1 - Etapas de um Estudo de Eventos

\section{Descrições das etapas}

(1) Definição do evento

Consiste em definir o evento e sua data de ocorrência, denominada de data zero.

(2) Critérios de seleção

Deve ser selecionada a janela do evento (L1), que é o período em que serão observados os preços dos títulos. A janela do evento abrange um período subsequente ao anúncio, para captar as reações após o evento, detectando evidências da velocidade e precisão do ajuste dos preços à nova informação liberada ao mercado; e um período anterior ao anúncio quando se admite a possibilidade de vazamento de informações, também denominadas de informações privilegiadas.

(3) Retornos normais e anormais

Tal etapa envolve a escolha do critério de mensuração dos retornos normais e anormais. Para isso, são utilizados modelos para a estimação dos retornos normais, classificados como estatísticos (modelo de mercado, por exemplo) ou econômicos (CAPM, por exemplo).

$$
A R_{i \tau}=R_{i \tau}-E\left(R_{i \tau} \mid X_{\tau}\right)
$$

$A R_{i \tau}$ : retorno anormal do ativo $i$ na data $\tau$; $R_{i i}$ : retorno real do ativo $i$ na data $\tau ; E\left(R_{i \tau} \mid X\right)$ : retorno estimado do ativo $i$ na data $\tau$, dado o retorno de $X$, representando o comportamento do mercado.

(4) Procedimento de estimação

Nesta etapa deve-se definir a janela de estimação (L0) que será utilizada para calcular os parâmetros do modelo de determinação dos retornos normais. 


\begin{tabular}{|l|}
\hline \multicolumn{1}{|c|}{ Descrições das etapas } \\
\hline (5) Procedimentos de teste \\
A quinta etapa corresponde ao procedimento de teste, em que é realizado o cálculo dos retornos anormais. \\
Nesse momento também se define a hipótese nula e as técnicas para a agregação dos retornos anormais. \\
\hline (6) Resultados empíricos \\
Esta etapa compreende a apresentação dos resultados empíricos obtidos com o emprego da metodologia. \\
\hline (7) Interpretações e conclusões \\
Nesta etapa final é o momento da interpretação dos resultados encontrados, respeitando-se o desenho \\
econométrico, com a observação de possíveis influências de outliers, principalmente em estudos \\
baseados em pequenas amostras. \\
Fonte: adaptado de Campbell, Lo e MacKinlay (1997).
\end{tabular}

Fonte: adaptado de Campbell, Lo e MacKinlay (1997).

A segunda etapa possui alto grau de subjetividade e arbitrariedade na delimitação da anela do evento. Camargos e Barbosa (2003) citam que as janelas não devem ser muito extensas, pois haveria o risco de se englobarem outros eventos, enviesando os resultados; e também não deve ser muito pequena, pois poderia deixar de captar a anormalidade ocorrida nos preços. Nesse contexto, o Estudo de Eventos aplicado à subscrição de ações, à emissão de títulos de dívida, ao pagamento de bonificações e/ou dividendos, a fusões e aquisições, entre outros, pode detectar a influência de notícias divulgadas ao mercado de capitais, como citam Silva, Carvalho e Nunes (2012), para quem o mercado de ações é movido por informações, ou seja, notícias que tendem a influenciar o comportamento do mercado, e indiretamente, a valorização acionária.

Cutler, Porteba e Summers (1989) detectaram que a variação do mercado acionário é reflexo das notícias do mundo financeiro e econômico. De forma mais detalhada, perceberam que as flutuações no valor das ações são atribuídas a uma série de fatores, sendo um deles a informação, o que comprova que o mercado reage a notícias, como, por exemplo, controle corporativo, política de regulamentação e condições macroeconômicas.

No Brasil, as notícias ligadas à política têm influenciado fortemente a variação das ações negociadas na $\mathrm{B}^{3 \text { (Brasil, Bolsa, Balcão) }}$, como: a aceitação do pedido de impeachment da presidente Dilma em 03 de dezembro de 2015 fez com que a B ${ }^{3}$ (Brasil, Bolsa, Balcão) subisse 5\% ao longo do dia, fechou com alta de 3,29\%, aos 46.393,26 pontos e R \$ 7,8 bilhões em negócios (Dias, 2015); e o Ibovespa chegou a subir quase 6\% nos primeiros negócios de 04 de março de 2016, caminhando para a maior elevação semanal desde 2008, com investidores reagindo à nova fase da operação Lava Jato envolvendo o Ex-Presidente Luiz Inácio Lula da Silva (BOVESPA..., 2016). 


\section{METODOLOGIA}

A população da pesquisa compreendeu todas as empresas listadas na $\mathrm{B}^{3 \text { (Brasil, }}$ Bolsa, Balcão) que aderiram ou migraram aos NDGCs no período de dezembro de 2000 a abril de 2015. Na consulta aos Boletins Diários de Informações (BDIs) divulgados

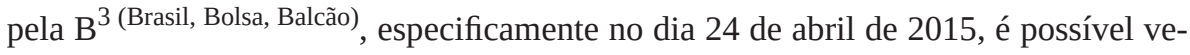
rificar que 133 empresas se encontravam no Novo Mercado; 30 empresas no Nível 1; 20 empresas no Nível 2; e, por fim, 8 no $\mathrm{B}^{3}$ Mais. Cabe destacar que por meio de busca nos BDIs anteriores foram incluídas as empresas que aderiram aos NDGCs e se desligaram em datas anteriores à realização da pesquisa.

Com a relação das empresas a serem analisadas, e considerando como a data do evento o dia de adesão ou migração de cada empresa, foi consultada a base de dados do Bloomberg, definindo-se o intervalo de 100 pregões antes e 100 pregões após a adesão ou a migração, atentando-se às seguintes observações: na amostra ocorreu a situação de uma mesma empresa realizar mais de um evento, ou seja, uma adesão e posterior(es) migração(ões); Initial Public Offerings (IPO), deslistagem, cisão e fusão foram desconsideradas; foram avaliados a liquidez diária das ações e o número de pregões antes e depois de cada evento, de modo que alguns eventos foram desconsiderados quando a empresa esteve ausente por mais de 20 pregões consecutivos ou apresentou poucas cotações; consideram-se indistintamente ações preferenciais e ordinárias; e, por último, desconsideram-se adesões e migrações, bem como pregões ocorridos entre junho e dezembro de 2008 em razão da crise financeira internacional.

Considerando a aplicação dos critérios estabelecidos, obtiveram-se 104 eventos considerando o Novo Mercado (NM), o Nível 1 (N1) e o Nível 2 (N2), segregados da seguinte forma: 55 casos referentes a ações ordinárias e 49 casos a ações preferenciais; 82 casos de adesão (N1=66; N2=10 e NM=15) e 22 de migração (N1 $\rightarrow \mathrm{N} 2=7$; $\mathrm{N} 2 \rightarrow \mathrm{NM}=4 ; \mathrm{N} 1 \rightarrow \mathrm{NM}=8 ; \mathrm{N} 1 \rightarrow \mathrm{N} 1=1 ; \mathrm{N} 2 \rightarrow \mathrm{N} 2=1$ e $\mathrm{NM} \rightarrow \mathrm{NM}=1$ ).

Uma condição necessária para a aplicação do método proposto para a averiguação do tamanho da janela do evento se refere à avalição de significância do evento, ou seja, à existência de retornos anormais. Para isso, Clemente et al. (2014) mostraram à existência de relação estatística significativa entre os eventos de adesão ou migração e o valor das ações, com evidência de resposta positiva do mercado de capitais, relatando o reconhecimento de que, por meio dos eventos de adesão e migração, as empresas aumentam seu compromisso com as práticas de Governança Corporativa, resultando em menor risco ao investidor. Na mesma linha, Carvalho e 
Pennacchi (2012) concluíram que as ações tendem a apresentar retorno positivo anormal quando as empresas aderem aos NDGCs.

Para o alcance do objetivo estabelecido, quatro etapas foram realizadas. A primeira, com os indicativos de resposta positiva do mercado às empresas que aderem e migram aos NDGCs citados no parágrafo anterior, aplicou-se metodologia para a determinação do melhor tamanho da janela do evento para as 104 empresas estudadas. Tal metodologia é detalhada por Antonelli et al. (2016), além de ser exemplificada no apêndice deste artigo, em que se tem como objetivo captar o melhor tamanho da janela do evento (janela de tamanho máximo), ou seja, identificar a janela que evidencia maior diferença entre os retornos estudados, caso a caso. Cabe destacar que foi utilizada na metodologia dessa primeira etapa um intervalo de 100 pregões antes e 100 pregões depois. Em todas as etapas de aplicação da referida metodologia, utilizou-se o Microsoft Excel®.

A segunda etapa consistiu na análise do tamanho das janelas obtidas para os 104 casos analisados, avaliando quais casos tiveram resultados (tamanhos de janela) diferentes da maioria, ou seja, maiores que a janela de tamanho máximo definida, os quais foram considerados como outliers.

Na sequência, a terceira etapa foi a seleção dos outliers, para os quais foram levantadas as notícias, caso a caso, na base de dados Bloomberg ${ }^{\circledR}$. Realizou-se, então, análise qualitativa das notícias divulgadas ao mercado no período da janela do evento encontrada na primeira etapa, buscando-se explicar a janela atípica encontrada. Vale citar que as notícias foram classificadas como positivas ou negativas em relação ao mercado. Nessa etapa, testaram-se as seguintes hipóteses:

$\mathrm{H}_{1}$ : A ocorrência de notícias próximas à janela de tamanho máximo influência negativamente no retorno das ações;

$\mathrm{H}_{2}$ : A ocorrência de notícias fora da janela de tamanho máximo influência positivamente no retorno das ações.

Para uma melhor compreensão de tais hipóteses, ambas as situações são demonstradas na Figura 1: 
Figura 1 - Hipótese da pesquisa

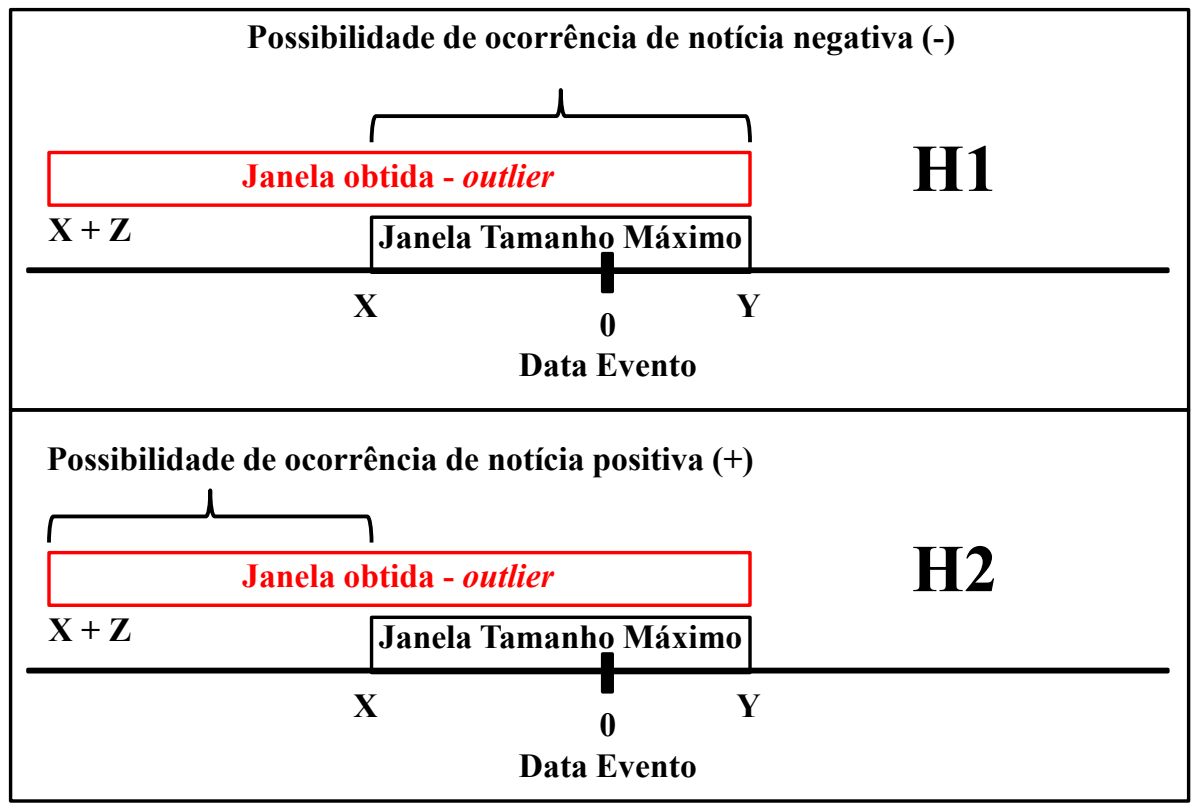

Fonte: os autores.

Por último, na quarta etapa, empregou-se o Estudo de Eventos para os casos considerados outliers na segunda etapa, considerando como o evento em estudo a(s) notícia(s) selecionada(s) na terceira etapa, a fim de comprovar as hipóteses levantadas na Figura 1 de que as notícias divulgadas dentro das janelas consideradas outliers tiveram influência no tamanho destas.

\section{ANÁLISE DOS RESULTADOS}

Nesta seção apresentam-se os resultados do estudo. Primeiro, discute-se o tamanho das janelas; depois, mostra-se a análise das notícias divulgadas no mercado; e, por último, os casos de outliers para verificar a sua influência no tamanho das janelas de eventos em casos de adesões e migrações aos NDGCs. 


\subsection{TAMANHO DAS JANELAS}

Os resultados demonstram que a janela 2-2 (2 pregões antes e 2 depois) foi a que melhor representou o evento para 38 casos (36,5\%). As janelas 2-5 e 5-2 também foram representativas, com 12 e 11 casos, respectivamente. Em conjunto, essas 3 janelas, acrescidas de um caso com janela 5-5, cobrindo apenas o intervalo de 5 pregões antes e 5 depois, representam 59,6\% da amostra. Esses resultados são apresentados no Gráfico 1.

Cabe citar a possibilidade de consideração de janelas maiores que 5-5. Adotando como limite a janela 10-10, abrange-se 69,2\% dos casos. Conforme se aumenta a janela máxima, mais casos são incorporados. Com a janela 15-15 como limite, tem-se 79,8\% da amostra. Nesta pesquisa optou-se pela consideração da janela máxima de 5-5 em razão da sua maior representatividade na amostra.

Gráfico 1 - Diagrama de Pareto para as janelas de evento (n=104)

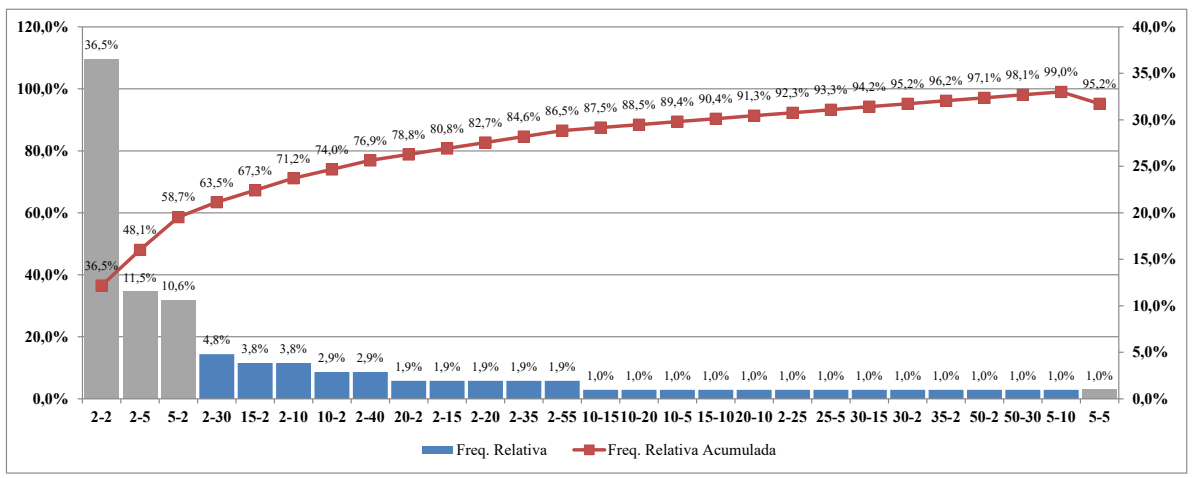

Fonte: os autores.

De acordo com o Gráfico 1, 86,5\% dos eventos são mais bem captados por janelas que não ultrapassam 15 pregões antecedentes e 55 subsequentes. Além da análise das janelas, também se buscou a identificação do pregão mais representativo para cada caso estudado, tanto no período anterior ao evento quanto posterior. No Gráfico 2 mostram-se os pregões anteriores ao evento: 
Gráfico 2 - Pregões antes do evento dos 104 casos estudados

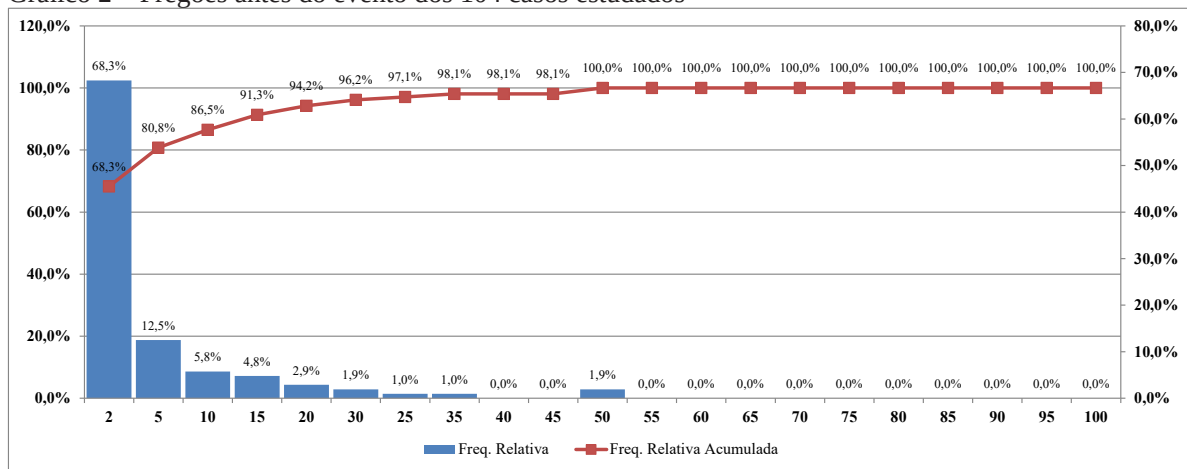

Fonte: os autores.

Conforme o Gráfico 2, em 71 casos (68,3\%) o pregão “2” é o mais representativo. Além disso, em 80,8\% dos casos o mais representativo ocorre até o pregão “5” anterior ao evento.

O Gráfico 3 refere-se aos pregões posteriores, com resultados similares à análise dos pregões anteriores:

Gráfico 3 - Pregões depois do evento dos 104 casos estudados

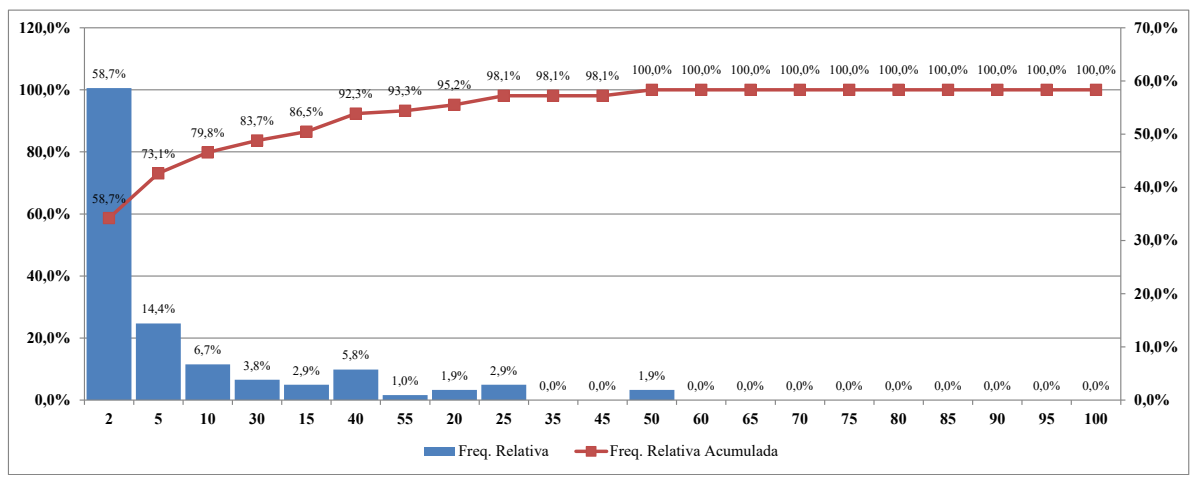

Fonte: os autores.

Como mostra o Gráfico 3, os pregões de maior representatividade são o “2” e o “5”, que abrangem conjuntamente $73,1 \%$ dos casos.

Destaca-se que esses resultados foram encontrados por meio de uma metodologia criteriosa, que considerou na sua construção conceitos amplamente aceitos, como retornos anormais e modelo estatístico de mercado. Para uma análise mais de- 
talhada, os 104 casos estudados são sumariados na Tabela 2, em que se observam as janelas mais representativas para cada um dos 104 casos estudados:

Tabela 2 - Janelas dos 104 casos (continua)

\begin{tabular}{|c|c|c|c|c|c|c|c|c|c|}
\hline Cód. & Ação & $\begin{array}{c}\text { An- } \\
\text { tes }\end{array}$ & Depois & $\begin{array}{c}\text { Jane- } \\
\text { la }\end{array}$ & Cód. & Ação & $\begin{array}{c}\text { An- } \\
\text { tes }\end{array}$ & $\begin{array}{l}\text { De- } \\
\text { pois }\end{array}$ & $\begin{array}{c}\text { Jane- } \\
\text { la }\end{array}$ \\
\hline 1 & ALL AMER LAT ON & 50 & 30 & $50-30$ & 53 & INEPAR ON & 2 & 2 & $2-2$ \\
\hline 2 & ALPARGATAS PN & 2 & 2 & $2-2$ & 54 & INEPAR PN & 2 & 2 & $2-2$ \\
\hline 3 & BANRISUL ON & 5 & 2 & $5-2$ & 55 & $\begin{array}{l}\text { INEPAR } \\
\text { TEL ON }\end{array}$ & 2 & 5 & $2-5$ \\
\hline 4 & BANRISUL PNA & 10 & 15 & $10-15$ & 56 & $\begin{array}{l}\text { IOCHP-MA- } \\
\text { XION ON }\end{array}$ & 2 & 2 & $2-2$ \\
\hline 5 & BRADESCO ON & 2 & 2 & $2-2$ & 57 & $\begin{array}{l}\text { IOCHP-MA- } \\
\text { XION PN }\end{array}$ & 20 & 2 & $20-2$ \\
\hline 6 & BRADESCO PN & 2 & 5 & $2-5$ & 58 & ITAÚ SA ON & 2 & 2 & $2-2$ \\
\hline 7 & BRADESPAR ON & 2 & 2 & $2-2$ & 59 & ITAÚSA PN & 2 & 2 & $2-2$ \\
\hline 8 & BRADESPAR PN & 2 & 2 & $2-2$ & 60 & $\begin{array}{l}\text { ITAÚUNI- } \\
\text { BANCO ON }\end{array}$ & 2 & 5 & $2-5$ \\
\hline 9 & BRASIL ON & 2 & 2 & $2-2$ & 61 & $\begin{array}{l}\text { ITAÚUNI- } \\
\text { BANCO PN }\end{array}$ & 5 & 2 & $5-2$ \\
\hline 10 & BRASIL PNCB & 35 & 2 & $35-2$ & 62 & $\begin{array}{l}\text { KLABIN AS } \\
\text { PN }\end{array}$ & 2 & 55 & $2-55$ \\
\hline 11 & BRASKEM PNA & 2 & 55 & $2-55$ & 63 & $\begin{array}{l}\text { KLABIN } \\
\text { S/A ON }\end{array}$ & 2 & 5 & $2-5$ \\
\hline 12 & BRF FOODS PN & 5 & 2 & $5-2$ & 64 & $\begin{array}{l}\text { KLABIN } \\
\text { S/A PN }\end{array}$ & 2 & 2 & $2-2$ \\
\hline 13 & CEEE-D ON & 10 & 2 & $10-2$ & 65 & $\begin{array}{l}\text { KROTON } \\
\text { ON }\end{array}$ & 2 & 2 & $2-2$ \\
\hline 14 & CEEE-GT ON & 50 & 2 & $50-2$ & 66 & $\begin{array}{l}\text { LIGHT SA } \\
\text { ON }\end{array}$ & 2 & 2 & $2-2$ \\
\hline 15 & CEEE-GT PN & 2 & 20 & $2-20$ & 67 & $\begin{array}{l}\text { MAGNESI- } \\
\text { TA SA ON }\end{array}$ & 2 & 35 & $2-35$ \\
\hline 16 & CELESC PNB & 2 & 2 & $2-2$ & 68 & $\begin{array}{l}\text { MARCOLO- } \\
\text { PO PN }\end{array}$ & 2 & 30 & $2-30$ \\
\hline 17 & CEMIG ON & 15 & 2 & $15-2$ & 69 & $\begin{array}{l}\text { METAL } \\
\text { LEVE ON }\end{array}$ & 2 & 10 & $2-10$ \\
\hline 18 & CEMIG PN & 10 & 2 & $10-2$ & 70 & NET PN & 2 & 2 & $2-2$ \\
\hline 19 & CESPE ON & 2 & 2 & $2-2$ & 71 & NET PN & 15 & 10 & $15-10$ \\
\hline 20 & CESPE PNA & 2 & 2 & $2-2$ & 72 & OI ON & 2 & 35 & $2-35$ \\
\hline 21 & CIAHERING ON & 2 & 2 & $2-2$ & 73 & OI PN & 2 & 20 & $2-20$ \\
\hline 22 & CONFAB PN & 5 & 2 & $5-2$ & 74 & $\begin{array}{l}\text { P. ACUCAR } \\
\text { PN }\end{array}$ & 5 & 2 & $5-2$ \\
\hline 23 & CONTAX ON & 2 & 40 & $2-40$ & 75 & $\begin{array}{l}\text { PARA- } \\
\text { NAPANE- } \\
\text { MA ON }\end{array}$ & 2 & 2 & $2-2$ \\
\hline
\end{tabular}


(continuação)

\begin{tabular}{|c|c|c|c|c|c|c|c|c|c|}
\hline Cód. & Ação & $\begin{array}{c}\text { An- } \\
\text { tes }\end{array}$ & Depois & $\begin{array}{c}\text { Jane- } \\
\text { la }\end{array}$ & Cód. & Ação & $\begin{array}{l}\text { An- } \\
\text { tes }\end{array}$ & $\begin{array}{l}\text { De- } \\
\text { pois }\end{array}$ & $\begin{array}{c}\text { Jane- } \\
\text { la }\end{array}$ \\
\hline 24 & CONTAX PN & 15 & 2 & $15-2$ & 76 & $\begin{array}{l}\text { PARA- } \\
\text { NAPANE- } \\
\text { MA ON }\end{array}$ & 2 & 2 & $2-2$ \\
\hline 25 & COPEL ON & 2 & 40 & $2-40$ & 77 & $\begin{array}{l}\text { PARA- } \\
\text { NAPANE- } \\
\text { MA PN }\end{array}$ & 2 & 2 & $2-2$ \\
\hline 26 & COPEL PNB & 2 & 40 & $2-40$ & 78 & PINE PN & 2 & 5 & $2-5$ \\
\hline 27 & CYRELLA REALT ON & 5 & 2 & $5-2$ & 79 & $\begin{array}{l}\text { POR- } \\
\text { TOBELLO } \\
\text { ON }\end{array}$ & 2 & 2 & $2-2$ \\
\hline 28 & DAYCOVAL PN & 2 & 30 & $2-30$ & 80 & $\begin{array}{l}\text { RANDON } \\
\text { PART PN }\end{array}$ & 2 & 5 & $2-5$ \\
\hline 29 & DROGASIL ON & 20 & 2 & $20-2$ & 81 & $\begin{array}{l}\text { ROSSI RE- } \\
\text { SID ON }\end{array}$ & 25 & 5 & $25-5$ \\
\hline 30 & ELETROBRAS ON & 2 & 2 & $2-2$ & 82 & SABESP ON & 5 & 2 & $5-2$ \\
\hline 31 & ELETROBRAS PNB & 2 & 2 & $2-2$ & 83 & $\begin{array}{l}\text { SANTOS } \\
\text { BRP UNT } \\
\text { N2 }\end{array}$ & 2 & 2 & $2-2$ \\
\hline 32 & ELETROPAULO PNA & 5 & 10 & $5-10$ & 84 & $\begin{array}{l}\text { SÃO CAR- } \\
\text { LOS ON }\end{array}$ & 30 & 2 & $30-2$ \\
\hline 33 & EMBRAER ON & 2 & 5 & $2-5$ & 85 & $\begin{array}{l}\text { SARAIVA } \\
\text { LIV PN }\end{array}$ & 2 & 2 & $2-2$ \\
\hline 34 & EQUATORIAL ON & 10 & 2 & $10-2$ & 86 & $\begin{array}{l}\text { SUZANO } \\
\text { PAPEL PNA }\end{array}$ & 2 & 25 & $2-25$ \\
\hline 35 & ESTACIO PART ON & 20 & 10 & $20-10$ & 87 & $\begin{array}{l}\text { SUZANO } \\
\text { PAPEL PNA }\end{array}$ & 2 & 2 & $2-2$ \\
\hline 36 & ETERNIT ON & 30 & 15 & $30-15$ & 88 & $\begin{array}{l}\text { TIM PART } \\
\text { S/A ON }\end{array}$ & 2 & 15 & $2-15$ \\
\hline 37 & ETERNIT ON & 2 & 5 & $2-5$ & 89 & $\begin{array}{l}\text { TRACTE- } \\
\text { BEL ON }\end{array}$ & 15 & 2 & $15-2$ \\
\hline 38 & ETERNIT PN & 10 & 5 & $10-5$ & 90 & $\begin{array}{l}\text { TRAN PAU- } \\
\text { LIST ON }\end{array}$ & 2 & 5 & $2-5$ \\
\hline 39 & EUCATEX PN & 2 & 2 & $2-2$ & 91 & $\begin{array}{l}\text { TRAN PAU- } \\
\text { LIST PN }\end{array}$ & 2 & 5 & $2-5$ \\
\hline 40 & FERBASA ON & 2 & 15 & $2-15$ & 92 & TUPY ON & 2 & 30 & $2-30$ \\
\hline 41 & FERBASA PN & 2 & 5 & $2-5$ & 93 & $\begin{array}{l}\text { ULTRAPAR } \\
\text { ON }\end{array}$ & 2 & 2 & $2-2$ \\
\hline 42 & FIBRIA ON & 2 & 2 & $2-2$ & 94 & $\begin{array}{l}\text { ULTRAPAR } \\
\text { PN }\end{array}$ & 10 & 20 & $10-20$ \\
\hline 43 & FIBRIA ON & 2 & 5 & $2-5$ & 95 & UNIPAR ON & 2 & 30 & $2-30$ \\
\hline 44 & FIBRIA PN & 2 & 2 & $2-2$ & 96 & $\begin{array}{l}\text { UNIPAR } \\
\text { PNB }\end{array}$ & 2 & 30 & $2-30$ \\
\hline 45 & FORJA TAURUS ON & 2 & 2 & $2-2$ & 97 & $\begin{array}{l}\text { USIMINAS } \\
\text { ON }\end{array}$ & 15 & 2 & $15-2$ \\
\hline 46 & FORJA TAURUS PN & 2 & 2 & $2-2$ & 98 & $\begin{array}{l}\text { USIMINAS } \\
\text { PNA }\end{array}$ & 2 & 2 & $2-2$ \\
\hline
\end{tabular}


(conclusão)

\begin{tabular}{clllclllllc}
\hline Cód. & \multicolumn{1}{c}{ Ação } & $\begin{array}{c}\text { An- } \\
\text { tes }\end{array}$ & Depois & $\begin{array}{c}\text { Jane- } \\
\text { la }\end{array}$ & Cód. & Ação & $\begin{array}{c}\text { An- } \\
\text { tes }\end{array}$ & $\begin{array}{c}\text { De- } \\
\text { pois }\end{array}$ & $\begin{array}{c}\text { Jane- } \\
\text { la }\end{array}$ \\
\hline 47 & FRAS-LE PN & 2 & 2 & $2-2$ & 99 & VALE ON & 2 & 2 & $2-2$ \\
48 & GERDAU MET PN & 2 & 2 & $2-2$ & 100 & VALE PNA & 2 & 2 & $2-2$ \\
49 & GERDAU PN & 5 & 5 & $5-5$ & 101 & WEB ON & 5 & 2 & $5-2$ \\
50 & IDEASNET ON & 5 & 2 & $5-2$ & 102 & WEG ON & 2 & 10 & $2-10$ \\
51 & IND ROMI ON & 5 & 2 & $5-2$ & 103 & WEG ON & 2 & 10 & $2-10$ \\
52 & INDUSVAL PN & 2 & 10 & $2-10$ & 104 & WEG PN & 5 & 2 & $5-2$ \\
\hline Fonte: & OS autores. & & & & & & & &
\end{tabular}

Percebe-se pelos resultados até aqui expostos que, de modo geral, as janelas menores captam melhor o reflexo dos eventos estudados. Nesse sentido, buscou-se realizar a separação dos casos que retornaram janelas maiores, os casos aqui denominados outliers. Na análise das janelas, 59,6\% dos casos mostraram janelas iguais ou inferiores ao tamanho (5-5), por isso consideradas de tamanho máximo. Na Tabela 2 foram destacados os outliers, ou seja, os casos que apresentam janelas superiores ao tamanho (5-5).

\subsection{ANÁLISE DAS NOTÍCIAS DIVULGADAS NO MERCADO}

Para os casos que apresentaram janelas maiores que (5-5), 42 de 104, foi realizada uma busca na base de notícias do Bloomberg ${ }^{\circledR}$ para o período das janelas encontradas, acrescida de três pregões antes e cinco depois, a fim de não restringir nenhuma notícia que pudesse ter influenciado o tamanho da janela. Essa análise possibilita a verificação da ocorrência das duas hipóteses citadas anteriormente, tendo como referência a janela de tamanho máximo (5-5).

Foram encontradas 29 notícias referentes a 26 dos 42 casos relacionados (62\%). Nas notícias encontradas, observa-se que $76 \%$ são positivas e apenas $24 \%$ negativas. Na Tabela 3 expõe-se a análise das notícias para os 26 casos: 


\begin{tabular}{|c|c|c|c|c|c|c|c|c|c|c|c|c|c|c|}
\hline Cód. & Ação & Tipo evento & Janela & Data Evento & Fonte Notícia & $\begin{array}{l}\text { Data } \\
\text { Notícia }\end{array}$ & $\begin{array}{c}\text { Classifi- } \\
\text { cação da } \\
\text { Notícia }\end{array}$ & Resumo da Notícia & Janela & $\begin{array}{c}\text { Pregões } \\
\text { Início } \\
\text { Janela }\end{array}$ & $\begin{array}{c}\text { Data } \\
\text { Notí- } \\
\text { cia }\end{array}$ & Evento & $\begin{array}{c}\text { Data } \\
\text { Notí- } \\
\text { cia }\end{array}$ & $\begin{array}{c}\text { Pregões } \\
\text { Final } \\
\text { Janela }\end{array}$ \\
\hline \multirow{3}{*}{1} & \multirow{3}{*}{$\begin{array}{l}\text { ALL AMER } \\
\text { LAT ON }\end{array}$} & \multirow{3}{*}{ Adesão N1 } & \multirow{3}{*}{$50-30$} & \multirow{3}{*}{$22 / 10 / 2010$} & FolhaNews & 09/11/2010 & Positiva & $\begin{array}{l}\text { Divulgação de aumento } \\
\text { de lucro }\end{array}$ & $50-30$ & -50 & & $22 / 10 / 2010$ & 18 & 30 \\
\hline & & & & & Bloomberg Brazilian News & $24 / 09 / 2010$ & Positiva & Previsão aumento receita & $50-30$ & -50 & -28 & $22 / 10 / 2010$ & & 30 \\
\hline & & & & & Bloomberg Brazilian News & $31 / 08 / 2010$ & Positiva & $\begin{array}{l}\text { Mudança de diretor-pre- } \\
\text { sidente }\end{array}$ & $50-30$ & -50 & -52 & $22 / 10 / 2010$ & & 30 \\
\hline \multirow{2}{*}{2} & \multirow{2}{*}{$\begin{array}{l}\text { BANRISUL } \\
\text { PNA }\end{array}$} & \multirow{2}{*}{ Adesão N1 } & \multirow{2}{*}{$10-15$} & \multirow{2}{*}{$31 / 07 / 2007$} & Agência Estado (AEB) & $13 / 08 / 2007$ & Positiva & $\begin{array}{l}\text { Previsão de novas emis- } \\
\text { sões de papéis }\end{array}$ & $10-15$ & -10 & & $31 / 07 / 2007$ & 13 & 15 \\
\hline & & & & & Bloomberg Brazilian News & $25 / 08 / 2007$ & Positiva & IPO de ações & $10-15$ & -10 & & $31 / 07 / 2007$ & 25 & 15 \\
\hline 3 & $\begin{array}{l}\text { BRASIL } \\
\text { PNCB }\end{array}$ & Adesão NM & $35-2$ & $28 / 06 / 2006$ & Agência Estado (AEB) & $26 / 05 / 2006$ & Positiva & $\begin{array}{l}\text { Papéis da empresa tem } \\
\text { maior alta }\end{array}$ & $35-2$ & -35 & -33 & 28/06/2006 & & 2 \\
\hline 4 & $\begin{array}{l}\text { BRASKEM } \\
\text { PNA }\end{array}$ & Adesão N1 & $2-55$ & $13 / 02 / 2003$ & Agência Estado (AEB) & $01 / 04 / 2003$ & Positiva & $\begin{array}{l}\text { Papéis da empresa tem } \\
\text { alta considerável }\end{array}$ & $2-55$ & -2 & & $13 / 02 / 2003$ & 47 & 55 \\
\hline 5 & $\begin{array}{l}\text { CEEE-D } \\
\text { ON }\end{array}$ & Adesão N1 & $10-2$ & $23 / 12 / 2010$ & Agência Estado (AEB) & 09/12/2010 & Positiva & $\begin{array}{l}\text { Ganho de leilão conces- } \\
\text { são de transmissão de } \\
\text { energia }\end{array}$ & $10-2$ & -10 & -14 & $23 / 12 / 2010$ & & 2 \\
\hline 6 & CEMIG ON & Adesão N1 & $15-2$ & $17 / 10 / 2001$ & $\begin{array}{l}\text { Agência Folha de Notícias } \\
\text { Ltda. (AFL) }\end{array}$ & 09/10/2001 & Positiva & $\begin{array}{l}\text { Papéis da empresa tem } \\
\text { maior alta }\end{array}$ & $15-2$ & -15 & -8 & $17 / 10 / 2001$ & & 2 \\
\hline \multirow[t]{2}{*}{7} & CEMIG PN & Adesão N1 & $10-2$ & $17 / 10 / 2001$ & $\begin{array}{l}\text { Agência Folha de Notícias } \\
\text { Ltda. (AFL) }\end{array}$ & $22 / 10 / 2001$ & Negativa & $\begin{array}{l}\text { Cemig descartada do } \\
\text { leilão da Copel }\end{array}$ & $10-2$ & -10 & & $17 / 10 / 2001$ & 5 & 2 \\
\hline & & & & & $\begin{array}{l}\text { Agência Folha de Notícias } \\
\text { Ltda. (AFL) }\end{array}$ & $17 / 10 / 2001$ & Negativa & $\begin{array}{l}\text { Previsão que o resultado } \\
\text { será afetado negativa- } \\
\text { mente }\end{array}$ & $15-2$ & -15 & & $17 / 10 / 2001$ & 0 & 2 \\
\hline \multirow[t]{2}{*}{8} & $\begin{array}{l}\text { CONTAX } \\
\text { ON }\end{array}$ & Adesão N2 & $2-40$ & $30 / 04 / 2013$ & Bloomberg First Word (BFW) & $02 / 05 / 2013$ & Negativa & Divulgação de prejuízo & $15-2$ & -15 & & $30 / 04 / 2013$ & 2 & 2 \\
\hline & CONTAX & & & & & & & & & & & & & \\
\hline 9 & PN & Adesão N2 & $15-2$ & $30 / 04 / 2013$ & Bloomberg First Word (BFW) & $05 / 02 / 2013$ & Negativa & Divulgação de prejuízo & $15-2$ & -15 & & 04/30/2013 & 2 & 2 \\
\hline
\end{tabular}


Ricardo Adriano Antonelli, Ademir Clemente, Romualdo Douglas Colauto

(continua)

\begin{tabular}{|c|c|c|c|c|c|c|c|c|c|c|c|c|c|c|}
\hline Cód. & Ação & Tipo evento & Janela & Data Evento & Fonte Notícia & $\begin{array}{c}\text { Data } \\
\text { Notícia }\end{array}$ & $\begin{array}{l}\text { Classifi- } \\
\text { cação da } \\
\text { Notícia }\end{array}$ & Resumo da Notícia & Janela & $\begin{array}{c}\text { Pregões } \\
\text { Início } \\
\text { Janela }\end{array}$ & $\begin{array}{c}\text { Data } \\
\text { Notí- } \\
\text { cia }\end{array}$ & Evento & $\begin{array}{c}\text { Data } \\
\text { Notí- } \\
\text { cia }\end{array}$ & $\begin{array}{c}\text { Pregões } \\
\text { Final } \\
\text { Janela }\end{array}$ \\
\hline 10 & COPEL ON & Adesão N1 & $2-40$ & $07 / 05 / 2008$ & Agência Estado (AEB) & $23 / 06 / 2008$ & Positiva & $\begin{array}{l}\text { Aneel autoriza reajuste } \\
\text { nas tarifas Copel }\end{array}$ & $2-40$ & -2 & & 07/05/2008 & 47 & 40 \\
\hline \multirow[t]{2}{*}{11} & $\begin{array}{l}\text { COPEL } \\
\text { PNB }\end{array}$ & Adesão N1 & $2-40$ & $07 / 05 / 2008$ & Agência Estado (AEB) & $14 / 05 / 2008$ & Negativa & $\begin{array}{l}\text { Divulgação de queda } \\
\text { no lucro }\end{array}$ & $2-40$ & -2 & & $07 / 05 / 2008$ & 7 & 40 \\
\hline & & & & & Agência Estado (AEB) & $15 / 05 / 2008$ & Negativa & $\begin{array}{l}\text { Papéis da empresa têm } \\
\text { maior queda }\end{array}$ & $2-40$ & -2 & & $07 / 05 / 2008$ & 8 & 40 \\
\hline 12 & $\begin{array}{l}\text { DAYCO- } \\
\text { VAL PN }\end{array}$ & $\begin{array}{l}\text { Migração } \\
\text { N1-N2 }\end{array}$ & $2-30$ & $16 / 05 / 2013$ & Bloomberg First Word (BFW) & 03/06/2013 & Negativa & $\begin{array}{l}\text { HSBC rebaixou reco- } \\
\text { mendação da Daycoval }\end{array}$ & $2-30$ & -2 & & $16 / 05 / 2013$ & 18 & 30 \\
\hline 13 & $\begin{array}{l}\text { DROGASIL } \\
\text { ON }\end{array}$ & Adesão NM & $20-2$ & 03/07/2007 & $\begin{array}{l}\text { Agência Folha de Notícias } \\
\text { Ltda. (AFL) }\end{array}$ & $21 / 06 / 2007$ & Positiva & $\begin{array}{l}\text { Oferta de ações ON para } \\
\text { o mercado }\end{array}$ & $20-2$ & -20 & -12 & 03/07/2007 & & 2 \\
\hline 14 & $\begin{array}{l}\text { ELETRO- } \\
\text { PAULO } \\
\text { PNA }\end{array}$ & Adesão N2 & $5-10$ & $13 / 12 / 2004$ & $\begin{array}{l}\text { Agência Folha de Notícias } \\
\text { Ltda. (AFL) }\end{array}$ & $20 / 12 / 2004$ & Positiva & $\begin{array}{l}\text { Liberação BNDES para } \\
\text { maior comercialização } \\
\text { de energia }\end{array}$ & $5-10$ & -5 & & $13 / 12 / 2004$ & 7 & 10 \\
\hline 15 & $\begin{array}{l}\text { ETERNIT } \\
\text { ON }\end{array}$ & Adesão N2 & $30-15$ & $02 / 03 / 2005$ & Bloomberg News (BN) & $24 / 02 / 2005$ & Positiva & $\begin{array}{l}\text { Divulgação de pagamen- } \\
\text { to de dividendos }\end{array}$ & $30-15$ & -30 & -6 & $02 / 03 / 2005$ & & 15 \\
\hline 16 & $\begin{array}{l}\text { ETERNIT } \\
\text { PN }\end{array}$ & Adesão N2 & $10-5$ & 08/03/2005 & Bloomberg News (BN) & $24 / 02 / 2005$ & Positiva & $\begin{array}{l}\text { Divulgação de pagamen- } \\
\text { to de dividendos }\end{array}$ & $10-5$ & -10 & -12 & 08/03/2005 & & 5 \\
\hline 17 & $\begin{array}{l}\text { KLABIN } \\
\text { AS PN }\end{array}$ & Adesão N1 & $2-55$ & $10 / 12 / 2002$ & Bloomberg News (BN) & $21 / 02 / 2003$ & Positiva & $\begin{array}{l}\text { Divulgação do maior } \\
\text { ganho das ações em } \\
\text { quatro anos }\end{array}$ & $2-55$ & -2 & & $10 / 12 / 2002$ & 73 & 55 \\
\hline 18 & $\begin{array}{l}\text { MAGNESI- } \\
\text { TA SA ON }\end{array}$ & Adesdão NM & $2-35$ & $02 / 04 / 2008$ & Bloomberg News (BN) & $28 / 04 / 2008$ & Positiva & $\begin{array}{l}\text { Papéis da empresa têm } \\
\text { alta considerável }\end{array}$ & $2-35$ & -2 & & $02 / 04 / 2008$ & 26 & 35 \\
\hline 19 & $\begin{array}{l}\text { MARCO- } \\
\text { LOPO PN }\end{array}$ & Adesão N2 & $2-30$ & 03/09/2002 & $\begin{array}{l}\text { Agência Folha de Notícias } \\
\text { Ltda. (AFL) }\end{array}$ & $24 / 09 / 2002$ & Positiva & $\begin{array}{l}\text { Ação é recomendada } \\
\text { para compra pela Corre- } \\
\text { tora Coinvalores }\end{array}$ & $2-30$ & -2 & & 03/09/2002 & 21 & 30 \\
\hline 20 & $\begin{array}{l}\text { METAL } \\
\text { LEVE ON }\end{array}$ & Adesão NM & $2-10$ & 05/07/2011 & Bloomberg Brazilian News & $30 / 06 / 2011$ & Positiva & $\begin{array}{l}\text { Divulgação de oferta } \\
\text { secundária de ações }\end{array}$ & $2-10$ & -2 & -5 & 05/07/2011 & & 10 \\
\hline 21 & OI ON & Adesão N1 & $2-35$ & 17/12/2012 & Valor Econômico & $23 / 01 / 2013$ & Positiva & Mudança de CEO & $2-35$ & -2 & & 17/12/2012 & 37 & 35 \\
\hline
\end{tabular}


(continua)

\begin{tabular}{|c|c|c|c|c|c|c|c|c|c|c|c|c|c|c|}
\hline Cód. & Ação & Tipo evento & Janela & Data Evento & Fonte Notícia & $\begin{array}{c}\text { Data } \\
\text { Notícia }\end{array}$ & $\begin{array}{l}\text { Classifi- } \\
\text { cação da } \\
\text { Notícia }\end{array}$ & Resumo da Notícia & Janela & $\begin{array}{c}\text { Pregões } \\
\text { Início } \\
\text { Janela }\end{array}$ & $\begin{array}{c}\text { Data } \\
\text { Notí- } \\
\text { cia }\end{array}$ & Evento & $\begin{array}{c}\text { Data } \\
\text { Notí- } \\
\text { cia }\end{array}$ & $\begin{array}{c}\text { Pregões } \\
\text { Final } \\
\text { Janela }\end{array}$ \\
\hline 22 & OI PN & Adesão N1 & $2-20$ & $17 / 12 / 2012$ & Valor Econômico & $23 / 01 / 2013$ & Positiva & Mudança de CEO & 2-35 & -2 & & $17 / 12 / 2012$ & 37 & 35 \\
\hline 23 & $\begin{array}{l}\text { TIM PART } \\
\text { S/A ON }\end{array}$ & Adesão NM & $2-15$ & 03/08/2011 & Bloomberg Brazilian News & $23 / 08 / 2011$ & Positiva & $\begin{array}{l}\text { Tim passa Claro e retoma } \\
2^{\circ} \text { lugar em clientes de } \\
\text { celular no País }\end{array}$ & $2-15$ & -2 & & 03/08/2011 & 20 & 15 \\
\hline 24 & TUPY ON & Adesão NM & $2-30$ & $17 / 10 / 2013$ & Bloomberg First Word (BFW) & $17 / 10 / 2013$ & Negativa & $\begin{array}{l}\text { Tupy tem maior queda } \\
\text { em dois meses após fixar } \\
\text { preço de oferta }\end{array}$ & $2-30$ & -2 & & $17 / 10 / 2013$ & 0 & 30 \\
\hline 25 & $\begin{array}{l}\text { ULTRA- } \\
\text { PAR PN }\end{array}$ & Adesão N1 & $10-20$ & $27 / 10 / 2005$ & Bloomberg News (BN) & $10 / 11 / 2005$ & Positiva & $\begin{array}{l}\text { Divulgação de lucro } \\
\text { trimestral }\end{array}$ & $10-20$ & -10 & & $27 / 10 / 2005$ & 14 & 20 \\
\hline 26 & $\begin{array}{l}\text { USIMINAS } \\
\text { ON }\end{array}$ & Adesão N1 & $15-2$ & $11 / 10 / 2007$ & Agência Estado (AEB) & $29 / 09 / 2007$ & Positiva & $\begin{array}{l}\text { Divulgação de bom } \\
\text { desempenho das ações da } \\
\text { empresa }\end{array}$ & $15-2$ & -15 & -12 & $11 / 10 / 2007$ & & 2 \\
\hline
\end{tabular}

Fonte: os autores.

De acordo com a Tabela 3, considerando a hipótese H1, foram encontradas sete notícias, consideradas negativas para a valorização acionária da empresa, o que pode ter influenciado na janela encontrada para tais casos. Como exemplo se tem os casos da CEMIG ON e CEMIG PN, que de acordo com a referida Tabela, obtiveram-se as janelas (15-2) e (10-2), respectivamente. Ocorre que, para tais ações, na mesma data da adesão ao N1 dos NDGCs, foi divulgada a notícia que o resultado da CEMIG seria afetado negativamente, o que pode ter influenciado o merca- 
do, refletindo na não obtenção de um retorno positivo pelo fato da adesão ao N1 dos NDGCs. Outro exemplo são os papéis da CONTAX ON e CONTAX PN, que na data próxima ao evento de adesão ao N2 tiveram divulgação de prejuízo.

Já para a hipótese $\mathrm{H} 2$ foram detectadas 22 notícias. A fim de exemplificação, tem-se a ALL AMER LAT ON, que foram publicadas duas notícias anteriores ao evento, as quais referenciam a previsão de aumento de receita e mudança de diretor-presidente. Ainda, foi encontrada uma terceira notícia posterior ao evento, que informa o aumento de lucro. Tais notícias podem explicar o fato de a metodologia ter detectado como melhor janela para o caso em questão a 50-30.

A empresa MARCOPOLO PN também teve publicada uma notícia positiva, que em aproximadamente 21 pregões após o evento a Corretora Coinvalores recomenda a compra dos papéis da Marcopolo. Considerando a janela obtida na Tabela 4 para a Marcopolo, que é de 2-30, a notícia citada também pode ter influenciado na ocorrência de tal janela.

Contudo, foram observados que dos 104 casos, obtiveram-se 62 casos com janelas limitadas ao intervalo 5-5. Para os 42 casos com janelas superiores, 26 podem ser explicados com as notícias descritas no Quadro 2. Tão logo, dos 104 casos, apenas 16 casos (15\%) não puderam ser explicados com as notícias analisadas, o que revela a necessidade de futuras pesquisas para explicar tais situações.

\subsection{CASOS OUTLIERS}

Considerando as notícias como o evento, empregou-se a metodologia do Estudo de Eventos com o modelo estatístico de mercado. Tal modelo relaciona o preço de um ativo com um índice de mercado, sendo possível expressá-lo por meio de uma regressão, um modelo estatístico. De acordo com MacKinlay (1997), tal modelo é matematicamente representado por meio de uma regressão linear simples:

$$
\mathrm{R}_{\mathrm{it}}=\alpha_{\mathrm{i}}+\beta_{\mathrm{i}} \mathrm{R}_{\mathrm{MT}}+\varepsilon_{\mathrm{it}}
$$

Em que:

$\mathrm{R}_{\mathrm{it}}$ : retorno do ativo na data $\mathrm{t}$;

$\alpha_{\mathrm{i}}$ : coeficiente de intercepto da regressão;

$\beta_{\mathrm{i}}$ : coeficiente da regressão que representa a declividade para o ativo i;

$\mathrm{R}_{\mathrm{mt}}$ : retorno da carteira de mercado na data $\mathrm{t}$. 
Como índice de mercado, utilizou-se o Ibovespa, que segundo a $\mathrm{B}^{3}$ (2015) "representa fielmente o comportamento médio das principais ações transacionadas, e o perfil das negociações à vista observadas nos pregões da Bovespa.” Como tamanho da janela do evento, utilizou-se a janela considerada dos não outliers da Tabela 4, ou seja, janela (5-5). Com isso, testou-se a significância estatística da relação entre preços das ações e índice de mercado para cada evento (notícia) dos casos considerados outliers. Com isso, a significância estatística indicará que a referida relação é verdadeira, o que, para isso, foi definido um nível de 95\% de confiança, ou seja, valor-p de 0,05. Diante de tais parâmetros, quando as relações entre os preços das ações e o índice de mercado para as notícias relacionadas forem significativas, tem-se a certeza de $95 \%$ de confiança que o teste espelha a realidade.

Para isso, foram inseridas no modelo variáveis dummies para indicar o período considerado como janela do evento $(d u m m y=1)$ e os períodos anterior e posterior ao evento $($ dummy $=0)$. Gujarati (2010) explica que, para se compararem as regressões a fim de identificar diferenças na inclinação, as $n$ observações (representadas pelas $n$ notícias de cada empresa) podem ser reunidas no seguinte modelo de estimação:

$$
\mathrm{R}_{\mathrm{it}}=\alpha+\beta_{1} \mathrm{R}_{\mathrm{mt}}+\beta_{2}\left(\mathrm{DM}_{\mathrm{it}} \mathrm{R}_{\mathrm{mt}}\right)+\beta_{3} \mathrm{DA}_{\mathrm{it}}+\varepsilon_{\mathrm{it}}
$$

Em que:

$\mathrm{DM}_{\mathrm{it}}$ e $\mathrm{DA}_{\mathrm{it}} 0$ na janela de estimação e comparação (anterior e posterior); $\mathrm{DM}_{\mathrm{it}}$ e $\mathrm{DA}_{\mathrm{it}}=1$ na janela do evento.

O $\beta_{2}$ é o coeficiente da inclinação diferencial. Tem-se a introdução das variáveis dummies multiplicativa (DM) e aditiva (DA). Para Gujarati (2010), a dummy na forma multiplicativa permite diferenciar os coeficientes de inclinação dos períodos. Logo, foram utilizadas dummies aditivas e multiplicativas.

A regressão stepwise por meio do Software Estatístico Livre R foi aplicada aos 26 casos da Tabela 4, sendo 25 de adesão (96,2\%) e 1 (3,8\%) de migração. Na Tabela 4 são apresentadas as quantidades dos testes em que nenhuma das dummies (janelas) se mostrou significativa, além dos casos em que ao menos uma das dummies multiplicativas se mostrou significativa: 
Tabela 4 - Significância das dummies

\begin{tabular}{|c|c|c|c|c|c|c|}
\hline Eventos & $\begin{array}{c}\text { Ne- } \\
\text { nhuma } \\
\text { Dummy }\end{array}$ & $\begin{array}{c}\text { Com } \\
\text { Dummy } \\
\text { aditiva }\end{array}$ & $\begin{array}{c}\text { Com } \\
\text { Dummy } \\
\text { multiplica- } \\
\text { tiva }\end{array}$ & $\begin{array}{l}\text { Com Dummies } \\
\text { Aditiva e Mul- } \\
\text { tiplicativa }\end{array}$ & $\begin{array}{c}\text { Com Dum- } \\
\text { mies } \\
\text { Aditiva ou } \\
\text { Multiplica- } \\
\text { tiva }\end{array}$ & Total casos \\
\hline Adesão & 20 & 4 & 3 & 1 & 6 & 25 \\
\hline Migração & 1 & 0 & 0 & 0 & 0 & 1 \\
\hline Total & 21 & 4 & 3 & 1 & 6 & 26 \\
\hline
\end{tabular}

Como se pode observar na Tabela 4, apenas 6 casos dos 26 (23,07\%) tiveram dummy(ies) representativas. Tal constatação indica que possivelmente outros fatores, além das notícias analisadas, podem estar influenciando a alteração da janela. Na sequência, os casos com dummy(ies) representativas são detalhados no Quadro 2:

Quadro 2 - Significância das dummies

\begin{tabular}{|l|l|l|}
\hline \multicolumn{1}{|c|}{ Caso } & \multicolumn{1}{|c|}{$\begin{array}{c}\text { Classificação } \\
\text { notícia }\end{array}$} & \multicolumn{1}{c|}{ Resumo notícia } \\
\hline ALL AMER LAT ON & Positiva & Divulgação de aumento de lucro \\
\hline BRASIL PNCB & Positiva & Papéis da empresa têm maior alta \\
\hline ETERNIT PN & Positiva & Divulgação de pagamento de dividendos \\
\hline KLABIN AS PN & Positiva & Divulgação do maior ganho das ações em quatro anos \\
\hline MAGNESITA SA ON & Positiva & Papéis da empresa têm alta considerável \\
\hline USIMINAS ON & Positiva & Divulgação de bom desempenho das ações da empresa \\
\hline
\end{tabular}

A relação de notícias divulgadas e a valorização acionária têm sido alvo de outras pesquisas, como, por exemplo, a de Lima et al. (2008), que avaliaram se a informação fornecida ao mercado de capitais, por meio da intenção de emissão de American Depositary Receipts (ADRs) por empresas brasileiras gerou retornos anormais nos preços das ações de tais companhias. Os achados indicam que tais notícias repercutiram na valorização do preço das ações das empresas, ainda que não de forma imediata.

A relação significativa encontrada de tais notícias com a valorização acionária indica a relevância destas, confirmando a Hipótese de Mercados Eficientes (Efficient Markets Hypothesis (EMH), que de acordo Fama (1970), os preços de mercado em qualquer instante refletem totalmente as informações disponíveis. De acordo com Cardoso e Martins (2012, p. 73), no início das pesquisas de EMH da década de 1960, “começou-se a notar que as respostas do mercado para determinados procedimentos 
contábeis (números contábeis) eram contraditórias ao esperado conforme preconizado pelas regras contábeis existentes à época." Com isso, observa-se que outros fatores podem influenciar na valorização acionária, como, por exemplo, as notícias divulgadas no mercado, as quais foram objeto de estudo na presente pesquisa.

Em relação aos achados da presente pesquisa, as notícias relacionadas que tiveram significância nas regressões realizadas são essencialmente notícias de lucros e distribuição de dividendos, o que fez que o evento de migração ou adesão aos NDGCs perdesse seu efeito perante tais notícias, gerando uma janela considerada neste estudo como outlier. Considerando as 22 notícias positivas detectadas no Quadro 2, que representam os 22 testes para H2, apenas seis foram comprovadas (22,7\%). Já para as sete notícias que representam H1 (notícia negativa), nenhuma foi comprovada.

Contudo, destaca-se não considerar que apenas a notícia analisada tenha influenciado na ocorrência de uma janela maior para os casos, mas um conjunto de fatores diversos, os quais devem ser pesquisados futuramente, que aliados às notícias analisadas, repercutiram de tal forma a gerar uma janela do evento superior ao limite estabelecido nesta pesquisa. Por último, tais resultados aqui encontrados podem contribuir nas etapas "não objetivas" do Estudo de Eventos, que segundo Camargos e Barbosa (2003, 2010), a escolha do tamanho da janela do evento ainda é realizada de forma subjetiva e arbitrária.

\section{CONCLUSÃO}

Na presente pesquisa teve-se como objetivo principal o estabelecimento de bases para um melhor entendimento da influência das notícias vinculadas ao mercado de capitais, na determinação do tamanho da janela a ser utilizada nos Estudos de Eventos relacionados com adesões e migrações aos NDGCs da B ${ }^{3}$ (Brasil, Bolsa, Balcão). Para isso, como proxy foram considerados os resultados de Carvalho e Pennacchi (2012) e Clemente et al. (2014), que detectaram a existência de retorno anormal positivo nos eventos de adesão ou migração aos NDGCs, evidenciando a resposta positiva do mercado de capitais ao evento estudado nesta pesquisa.

Após a determinação do tamanho da janela, para os casos que resultassem em tamanhos de janelas diferentes da maioria dos elementos da amostra, foi realizada a análise das notícias divulgadas ao mercado de capitais no período da janela do evento encontrada, a fim de entender os resultados encontrados. 
Na análise dos 104 casos com o emprego da metodologia de Antonelli et al. (2016), os achados demonstram uma tendência de pequenas janelas do evento, limitadas a (5-5), com cerca de 59,6\% dos casos (62 de 104). Dos 42 casos considerados outliers (com janela maior que (5-5)), foram encontradas notícias para 26 (61,9\%), dos quais apenas seis casos se obtiveram dummies significativas (23,07\%). Contudo, dos 104 casos analisados, tem-se 68 casos em que o evento (adesão, migração ou notícia) foi explicado pela metodologia utilizada, representando 65,4\% dos casos.

Há de se ressaltar que, das notícias que obtiveram dummies significativas, apenas as positivas tiveram significância. Vale lembrar que os eventos de adesão e migração aos NDGCs são considerados notícias positivas pelo mercado. Logo, no uso da metodologia desta pesquisa, observa-se que na determinação do tamanho da janela do evento as notícias negativas demonstram não influenciar como as positivas.

É importante lembrar que o estabelecimento da janela limite do evento é importante e decisiva, pois o aumento da janela 5-5 reflete em menos outliers. A fim de esclarecimento, caso fosse considerado como limite de janela a 15-15, ter-se-ia apenas 21 outliers (e não 26 como na janela 5-5), dos quais 16 com notícias detectadas e oito (metade) com dummies significativas. Com isso, o percentual de explicação dos casos aumentaria para 87,5\%, em vez de 65,4\% com a janela (5-5). Tais informações relatam a importância da definição da janela limite, o que poderá influenciar diretamente nos resultados sequentes.

Nesse contexto, os achados indicam que o uso de pesquisas com grandes janelas de evento para medir os efeitos de adesão ou migração aos NDGCs podem estar equivocados, e ainda, que os estudos com pequenas janelas têm maior chance de efetivamente capturar o evento, além de menores riscos de capturar ruídos de outros eventos. Tais resultados estão alinhados às considerações de Camargos e Barbosa (2003), em que o tamanho da janela do evento deve englobar períodos considerados relevantes e não deve ser muito extensa, pois haveria o risco de se englobar a outros eventos, enviesando os resultados. Ainda se destaca que os resultados desta pesquisa também estão alinhados aos achados de Colombo e Galli (2010), que ao testarem uma variedade de janelas de evento entre 20 dias antes e 20 dias após o registro, encontraram evidências de que o intervalo 5-5 apresenta ganhos anormais estatisticamente positivos a 5\% de significância.

Considerando os resultados encontrados, os objetivos desta pesquisa foram alcançados, viabilizando sua utilização em outros estudos que envolvem a definição do tamanho da janela do evento. Contudo, destacam-se algumas limitações da pesquisa: a impossibilidade de generalização dos resultados para qualquer evento e os re- 
sultados encontrados são válidos somente para pesquisas que utilizarão o estudo de eventos em situações de adesão ou migração aos NDGCs da B ${ }^{3}$ (Brasil, Bolsa, Balcão), muito embora tal metodologia possa ser utilizada em outros eventos.

Destarte, levando-se em conta os resultados encontrados, bem como as limitações existentes, indicam-se para pesquisas futuras: replicação do estudo para outros tipos de eventos; emprego da metodologia em outros mercados de capitais; e estudo focado na possível influência de notícias negativas na determinação do tamanho da janela de eventos, visto que nesta pesquisa nenhuma notícia negativa teve influência.

\section{REFERÊNCIAS}

ANTONELLI, R. A. et al. Adesão e Migração aos Níveis Diferenciados de Governança Corporativa: Investigação da Janela do evento. Contabilidade, Gestão e Governança, v. 19, n. 1, p. 23-48, 2016.

BALL, R.; BROWN, P. An empirical evaluation of accounting numbers. Journal of Accounting Research, v. 6, i. 2, p. 159-178, 1968.

BATISTELLA, F. D. et al. Retornos de Ações e Governança Corporativa: Um Estudo de Eventos. In: CONGRESSO USP DE CONTROLADORIA E CONTABILIDADE, 4., 2014, São Paulo. Anais... São Paulo: USP, 2014.

B B $^{3}$ BRASIL, BOLSA, BALCÃO. 2015. Disponível em: <http://www.bmfbovespa. com.br $\geq$. Acesso em: 02 nov. 2015.

BERLE, A. A.; MEANS, G. C. A moderna sociedade anônima e a propriedade privada. In: AZEVEDO, D. A. Os Economistas. Rio de Janeiro: Abril Cultural, 1984.

BERNARDINHO, F. F. M. et al. Governança Corporativa e o valor da firma: um estudo de empresas brasileiras do setor elétrico. Revista Eletrônica de Ciência Administrativa (RECADM), v. 13, n. 2, p. 185-202, 2014.

BOVESPA opera em forte alta no final da semana. G1, 04 mar. 2016. Disponível em: <http:/g1.globo.com/economia/mercados/noticia/2016/03/bovespa-cotacao-de-04-03-16.html>. Acesso em: 09 mar. 2016.

\section{CADBURY. Report of the Committee on the Financial Aspects of Corporate}

Governance. London: GEE, 1992. Disponível em: <http://www.ecgi.org/codes/documents/cadbury.pdf $\geq$. Acesso em: 02 nov. 2015. 
CAMARGOS, M. A.; BARBOSA, F. V. Adesão aos níveis diferenciados de governança corporativa (NDGC), criação de valor e liquidez: evidências empíricas. In: ENCONTRO NACIONAL DE ENGENHARIA DE PRODUÇÃO - ENEGEP, 16. Fortaleza, 2006. Anais... Fortaleza: ABEPRO, 2006.

CAMARGOS, M. A.; BARBOSA, F. V. A adoção de práticas diferenciadas de governança corporativa beneficia o acionista e aumenta a liquidez acionária? Evidências empíricas do mercado brasileiro. Revista de Gestão da USP - REGE, v. 17, n. 2, p. 189-208, 2010.

CAMARGOS, M. A.; BARBOSA, F. V. Estudo de eventos: teoria e operacionalização. Caderno de Pesquisas em Administração, v. 10, n. 3, 2003.

CAMPBELL, J. Y.; LO, A. W.; MACKINLAY, A. C. The econometrics of financial markets. 2. ed. New Jersey: Princeton University Press, 1997.

CARDOSO, R. L.; MARTINS, V. A. Hipótese de Mercado Eficiente e Modelo de Precificação de Ativos Financeiros. In: IUDÍCIBUS, S. D.; LOPES, A. B. (Org.). Teoria avançada da contabilidade. 2. ed. São Paulo: Atlas, 2012.

CARLESSO NETO, O. Retorno e Risco das Carteiras de Governança Corporativa no Mercado de Capitais Brasileiro: uma análise multiperíodo. 2014. 156 p. Dissertação (Mestrado em Administração)-Universidade Federal de Uberlândia, Minas Gerais, 2014.

CARVALHO, A. G. Governança Corporativa no Brasil em Perspectiva. Revista de Administração da USP (RAUSP), v. 37, n. 3, p. 19-32, 2002.

CARVALHO, A. G.; PENNACCHI, G. G. Can a stock exchange improve corporate behavior? Evidence from firms' migration to premium listings in Brazil. Journal of Corporate Finance, v. 18, i. 4, p. 883-903, 2012.

CATAPAN, A.; COLAUTO, R. D. Governança corporativa: uma análise de sua relação com o desempenho econômico-financeiro de empresas cotadas no Brasil nos anos de 2010-2012. Contaduría y Administración, v. 59, n. 3, p. 137-164, 2014.

CLEMENTE, A. et al. O mercado brasileiro precifica a adesão e a migração aos níveis diferenciados de Governança Corporativa? Revista de Administração e Contabilidade da Unisinos, v. 11, n. 2, p. 140-152, 2014.

COASE, R. H. The nature of the firm. Econômica, v. 4, n. 16, p. 386-405, 1937. 
COLOMBO, J. A.; GALLI, O. C. Governança corporativa no Brasil: Níveis de governança e rendimentos anormais. Revista Portuguesa e Brasileira de Gestão, v. 9, n. 4, p. 26-37, 2010.

COMERLATO, G. M. B.; TERRA, P. R. S.; BRAGA, L. O. A reação do mercado acionário brasileiro às novas regras de governança corporativa da BOVESPA - um estudo empírico sobre o Nível 1. In: CONGRESSO BRASILEIRO DE CUSTOS, 9., 2002. São Paulo. Anais... São Paulo: Associação Brasileira de Custos, 2002.

CORRADO, C. J. Event studies: A methodology review. Accounting \& Finance, v. 51, i. 1, p. 207-234, 2011.

COSTA, A. R.; CAMARGOS, M. A. Análise Empírica da Adesão aos Níveis Diferenciados de Governança Corporativa da Bovespa sobre o Retorno dos Acionistas. Revista de Gestão USP, v. 32, n. 1, p. 31-42, 2006.

CUTLER, D. M.; PORTEBA, J. M.; SUMMERS, L. H. What moves stock prices? Journal of Portifolio Management, v. 15, n. 3, 1989.

DENIS, D.; McCONNEL, J. International corporate governance. Journal of Financial and Quantitative Analysis, v. 38, n. 1, p. 1-36, 2003.

DIAS, P. Dólar cai e Bolsa tem forte alta com expectativa sobre impeachment. Estadão, 03 dez. 2015. Disponível em: <http://economia.estadao.com.br/noticias/mercados,abertura-de-impeachment-contra-dilma-anima-investidores-e-empresas-es-

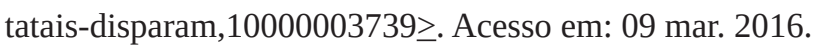

DOLLEY, J. C. Characteristics and procedure of common stock split-ups. Harvard Business Review, v. 11, p. 316-326, 1933.

FAMA, E. F. Efficient Capital Markets: A review of theory and empirical work. The Journal of Finance, v. 25, i. 2, p. 383-417, 1970.

FAMA, E. F. et al. The adjustment of stock prices to new information. International Economic Review, v. 10, i. 1, p. 1-21, 1969.

GUJARATI, D. N. Econometria Básica. 3. ed. São Paulo: Pearson Makron Books, 2010. 
JENSEN, M.; MECKLING, W. Theory of the firm: managerial behavior, agency cost and ownership structure. Journal of Financial Economics, v. 3, i. 4, 305-360, 1976.

LAMOUNIER, W. M.; NOGUEIRA, E. M. Estudo de Eventos: Procedimentos e Estudos Empíricos. In: SEMINÁRIO DE GESTÃO DE NEGÓCIOS - UM ENFOQUE ACADÊMICO NA REALIDADE EMPRESARIAL, 2., 2005, Curitiba. Anais... Curitiba, 2005.

LEAL, R. P. C.; CARVALHAL-DA-SILVA A. L. Corporate governance and value, in Brazil (and in Chile). Inter-American Development Bank, Latin American Research Network. Research Network, Working Paper, 2005.

LEAL, R. P. C.; CARVALHAL-DA-SILVA, A. L. Corporate governance index, firm valuation and performance in Brazil. Rio de Janeiro: COPPEAD/UFRJ, 2004.

LIMA, I. S.; MALACRIDA, M. J. C. Um Estudo da Eficiência Informacional do Mercado Acionário Brasileiro. Revista de Informação Contábil, v. 2, n. 1, 1-18, 2008.

MACKINLAY, A. C. Event studies in economics and finance. Journal of Economic Literature, Nashville: American Economic Association, v. 35, i. 1, 1997.

MARQUES, V. A. et al. Relação entre Níveis de Governança, Política de Dividendos, Endividamento e Valor das Empresas Brasileiras. Revista Evidenciação Contábil \& Finanças, v. 3, n. 2, p. 4-26, 2015.

MICHALISCHEN, F. Evidências da migração de empresas de capital aberto para os níveis diferenciados de governança corporativa da Bovespa: um estudo de eventos. 2008. 166 p. Dissertação (Mestrado em Administração - Universidade de São Paulo, São Paulo, 2008.

NAKAYASU, G. N. O impacto do anúncio e da adesão das ações aos níveis diferenciados de governança corporativa no Brasil. 2006. 134 p. Dissertação (Mestrado em Administração) - Universidade de São Paulo, São Paulo, 2006.

NEVES, L. C.; LEMES, S. Efeitos no retorno e na liquidez média das ações de empresas que emitiram ADRs na Nyse e das que aderiram ao Novo Mercado. Revista Universo Contábil, v. 5, n. 3, p. 24-42, 2009. 
NISHI, L. F. Adesão aos níveis de Governança Corporativa da Bovespa: Um Estudo de Evento. 2003, 119 p. Dissertação (Mestrado em Economia)-Universidade Federal de Santa Catarina, Florianópolis, 2003.

ORGANISATION FOR ECONOMIC CO-OPERATION AND DEVELOPMENT. Principles of Corporate Governance, 2004. Disponível em: <http://www.oecd.

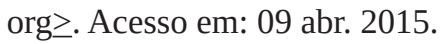

PIRES, M. A. ADRs e Governança Corporativa: um estudo de eventos sobre o comportamento das ações negociadas no Brasil. 2006. 215 p. Dissertação (Mestrado em Ciências Contábeis) - Fundação Instituto Capixaba de Pesquisas em Contabilidade, Economia e Finanças, Vitória: FUCAPE, 2006.

RODRIGUES, M. M. S. et al. Estudo Comparativo das Empresas do Setor Energético que Aderiram a Níveis Diferenciados de Governança Corporativa. Revista Economia e Gestão (E\&C), v. 15, n. 38, p. 29-59, 2015.

SANTOS, D. F. et al. Governança Corporativa: o preço das ações tem melhores resultados com a inclusão das companhias da BOVESPA no IGC? In: SEMINÁRIO INTERNACIONAL DE INTEGRAÇÃO E DESENVOLVIMENTO REGIONAL, 1., 2013, Ponta Porã. Anais... Ponta Porã: UEMS, 2013.

SILVA, C. A. T.; CARVALHO, C. C.; NUNES, D. M. S. O Que Move o Preço da Ação? Uma Abordagem sobre a Influência das Notícias no Mercado Acionário.

REUNIR - Revista de Administração, Contabilidade e Sustentabilidade, v. 2, n. 3, p. 1-13, 2012.

SILVA, C. C. S.; MARTINS, O. S. Valor e Práticas de Governança Corporativa das Empresas Listadas na BM\&FBovespa. Revista de Gestão, Finanças e Contabilidade, v. 5, n. 3, p. 26-41, 2015.

SIRQUEIRA, A. B.; KALATZIS, A. E. G. Boas Práticas de Governança Corporativa e Otimização de Portfólio: Uma Análise Comparativa. In: ENCONTRO NACIONAL DE ECONOMIA, 34., 2006, Salvador. Anais... Salvador: ANPEC, 2006.

SOUZA, E. M.; MARCON, R. Desempenho econômico e de mercado das empresas conforme sua classificação nos níveis de Governança Corporativa. In: ENCONTRO NACIONAL DE ENGENHARIA DE PRODUÇÃO - ENEGEP, 16., 2006, Fortaleza. Anais... Fortaleza: ABEPRO, 2006. 
VILHENA, F. A. C.; CAMARGOS, M. A. Governança Corporativa, Criação de Valor e Desempenho Econômico-Financeiro: Evidências do Mercado Brasileiro com dados em Painel, 2005-2011. Revista de Gestão - REGE, v. 22, n. 1, p. 77-96, 2015.

WILLIAMSON, O. E. Comparative Economic Organization: The Analysis of Discrete Structural Alternatives. Administrative Science Quarterly, v. 36, i. 2, p. 269296, 1991.

\section{Como citar este artigo:}

\section{ABNT}

ANTONELLI, Ricardo Adriano; CLEMENTE, Ademir; COLAUTO, Romualdo Douglas. Notícias do mercado de capitais e janelas de eventos para adesões e migrações aos NDGCs. RACE, Revista de Administração, Contabilidade e Economia, Joaçaba: Ed. Unoesc, v. 17, n. 1, p. 245-282, jan./abr. 2018. Disponível em: <http://editora.unoesc.edu.br/index.php/race>. Acesso em: dia/mês/ano.

\section{APA}

Antonelli, R. A.; Clemente, A.; Colauto, R. D. (2018). Notícias do mercado de capitais e janelas de eventos para adesões e migrações aos NDGCs. RACE, Revista de Administração, Contabilidade e Economia, 17(1), 245-282. Recuperado em dia/mês/ ano, de http://editora.unoesc.edu.br/index.php/race 


\section{APÊNDICE - DETALHAMENTO DA METODOLOGIA PARA ESTIMAR A JANELA MAIS REPRESENTATIVA}

\section{METODOLOGIA PARA DETERMINAÇÃO DO MELHOR TAMANHO DA JANELA DO EVENTO}

Para a aplicação da metodologia a ser descrita, alguns parâmetros iniciais devem ser definidos. Como primeiro parâmetro, optou se pelo modelo estatístico de mercado, com base em MacKinlay (1997), com o uso de uma carteira hipotética de mercado, o Índice Bovespa (Ibovespa). A escolha do Ibovespa deu-se pela sua representatividade, que segundo a própria BM\&FBovespa (2015), tal índice tem a finalidade de servir como um indicador médio de comportamento de mercado, representando fielmente o comportamento médio das principais ações transacionadas na BM\&FBovespa.

O segundo parâmetro refere-se ao número de pregões antes e depois da data do evento. Neste momento, indica-se a utilização de um intervalo com vários pregões, para que se possibilite a análise mais abrangente das eventuais variações dos tamanhos das janelas do evento, de acordo com o método de que será descrito a seguir. Desta forma, para a presente pesquisa, optou-se por um intervalo de 100 pregões antes e 100 pregões depois. Com isso, tais janelas serão reduzidas de 5 em 5 pregões, sendo que ao final, da janela 5 antes e 5 depois (5-5) será reduzida para 5-2, 2-5, 2-2, esta última que é a janela de tamanho mínimo a ser considerada. A fim de esclarecimento, as janelas pesquisadas podem ser visualizadas na Figura 3 (item "a”), e como é montado uma matriz, todas as combinações possíveis de janelas são analisadas pela metodologia.

Após os parâmetros iniciais definidos, são realizadas as seis etapas, os quais são descritas a seguir.

\subsection{Cálculo do retorno das Ações e do Ibovespa}

Para cada caso analisado (104 no total), com os valores das ações e do Ibovespa, foram realizados os cálculos do retorno das ações para as 21 janelas antes do evento (2, 5, 10...100 pregões) e as 21 depois. Para isso, primeiramente são transformados os valores absolutos de preço de cada ação e do Ibovespa em índices de mesma data-base, conforme a Equação (1), exemplificado na Figura $1^{1}$ (item “a”).

\footnotetext{
${ }^{1}$ A data de 12/12/03 na Figura 1 é a data do evento de adesão ao N1 da ação "VALE ON".
} 
Índice do ativo ${ }_{i t}=\left(\frac{\mathrm{Vlr}_{\mathrm{it}}}{\mathrm{Vlr}_{0}}\right) \times 100$

Em que,

$\mathrm{Vlr}_{\mathrm{it}}$ : valor do ativo na data $\mathrm{t}$;

$\mathrm{Vlr}_{\mathrm{o}}$ : valor do ativo na data zero;

Em seguida, o retorno para cada uma das 42 janelas (21 antes e 21 depois) é calculado por meio da Equação (2), conforme demonstrado na Figura 1, utilizando como exemplo a ação VALE ON (Vale S/A).

Retorno anormal da célula ${ }_{i t}=\frac{\text { Ação }_{i t}}{\text { Ibovespa }_{t}}$

Em que,

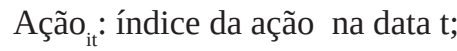

Ibovespa $\mathrm{t}_{\mathrm{t}}$ índice do Ibovespa na data t;

\begin{tabular}{|c|c|c|c|c|c|}
\hline \multicolumn{6}{|c|}{ Transformação Índices - Equação "1" } \\
\hline Data & Pregões & $\begin{array}{c}\text { Cotação } \\
\text { Vale ON }\end{array}$ & Ibovespa & $\begin{array}{l}\text { Retorno } \\
\text { Vale ON }\end{array}$ & $\begin{array}{l}\text { Retorno } \\
\text { Ihovespa }\end{array}$ \\
\hline $25 / 07 / 03$ & -100 & $13.750,30$ & 6,52 & 103,97 & 115,15 \\
\hline $28 / 07 / 03$ & -99 & $13.643,30$ & 6,58 & 103,16 & 116,33 \\
\hline $29 / 07 / 03$ & -98 & $13.623,30$ & 6,63 & 103,01 & 117,15 \\
\hline$\vdots$ & $\vdots$ & $\vdots$ & $\vdots$ & $\vdots$ & $:$ \\
\hline $10 / 12 / 03$ & -2 & $20.972,60$ & 10,58 & 158,58 & 187,04 \\
\hline $11 / 12 / 03$ & -1 & $21.296,30$ & 10,42 & 161,03 & 184,14 \\
\hline $12 / 12 / 03$ & 0 & $20.973,90$ & 10,90 & 158,59 & 192,53 \\
\hline $15 / 12 / 03$ & 1 & $20.709,70$ & 11,00 & 156,60 & 194,36 \\
\hline $16 / 12 / 03$ & 2 & $20.759,50$ & 11,02 & 156,97 & 194,73 \\
\hline$:$ & $:$ & $:$ & $\vdots$ & : & $:$ \\
\hline \multicolumn{6}{|c|}{ Cálculo Retorno Anormal - Equação "2" } \\
\hline \multicolumn{6}{|c|}{ Ret. Anormal Vale $-2=187,04 / 158,58=1,18$} \\
\hline \multicolumn{6}{|c|}{ Ret. Anormal Vale $2=194,73 / 156,97=1,24$} \\
\hline & & (a) & & & \\
\hline
\end{tabular}

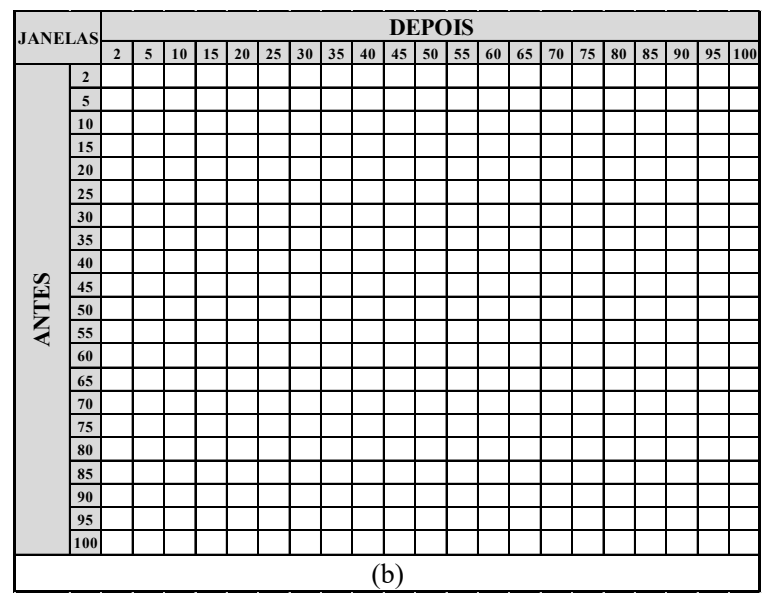

Figura 1 - Matriz de Janelas e Cálculo Retorno da ação VALE ON

Fonte: dados da Pesquisa

\subsection{Cálculo do retorno das Janelas}

Com a obtenção dos 42 retornos anormais, para cada caso dos 104 estudados, faz-se necessário o preenchimento da matriz de janelas exposta na Figura 1 (item “b”). Para isso, utiliza-se a Equação (3). 
Retorno diferencial da janela $_{\mathrm{i}}=\frac{\text { Retorno Depois }_{\mathrm{ij}}}{\text { Retorno Antes }_{\mathrm{ij}}}$

Em que,

Retorno Depois $\mathrm{ij}_{\mathrm{j}}$; retorno posterior relativo ao ativo na janela j;

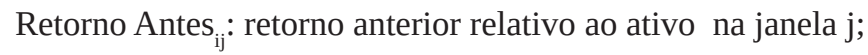

\subsubsection{Cálculo do retorno equivalente diário}

O terceiro passo da metodologia proposta é a transformação do retorno diferencial de cada janela, obtido na Equação (3) em retorno equivalente diário, por meio da Equação (4).

Ret. equivalente da janela $_{i}=$ Ret. da janela $_{i} \frac{1}{\text { pregões }_{i}}$

Em que,

Retorno da Janela $\mathrm{i}_{\mathrm{i}}$ : retorno diferencial da janela i;

Pregões $_{\mathrm{i}}$ : total de pregões antes e depois da janela i;

Na Tabela 1 é mostrado o resultado para um evento da ação VALE ON.

Tabela 1 - Matriz de janelas para evento da ação VALE ON

\begin{tabular}{|c|c|c|c|c|c|c|c|c|c|c|c|c|c|c|c|c|c|c|c|c|c|c|}
\hline \multirow{2}{*}{\multicolumn{2}{|c|}{ JANELAS }} & \multicolumn{21}{|c|}{ DEPOIS } \\
\hline & & 2 & 5 & 10 & 15 & 20 & 25 & 30 & 35 & 40 & 45 & 50 & 55 & 60 & 65 & 70 & 75 & 80 & 85 & 90 & 95 & 100 \\
\hline \multirow{14}{*}{ 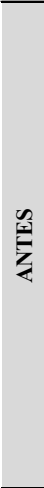 } & 2 & 0127 & 1,0051 & 1,0034 & 1,0003 & 0,9993 & 0,9991 & 0,9992 & 1,0020 & 1,0011 & & & 9994 & 0,9994 & 0,9993 & 0,9999 & 0,9995 & 0,9991 & 0,9997 & 0,9989 & 0,9994 & \\
\hline & 5 & 0175 & 1,0108 & 1,0075 & 1,0038 & 1,0022 & 0016 & 1,0013 & 36 & & & & 007 & 1,0005 & 1,0004 & 008 & 1,0004 & 1,0000 & 0005 & 9996 & 0002 & \\
\hline & 15 & 0109 & 1,0085 & 1,0070 & 1,0046 & 1,0034 & 1,0027 & 1,0024 & \begin{tabular}{|l|}
1,0041 \\
\end{tabular} & 1,0033 & 1,0036 & 1,0030 & 1,0014 & 1,0013 & 1,0011 & 1,0015 & 1,0010 & 1,0006 & 010 & 003 & 007 & \\
\hline & 20 & 0060 & 1,0047 & 1,0041 & 1,0025 & 1,0017 & 1,0013 & 1,0011 & 28 & 1,0022 & 1,0 & & & & & & 1,0004 & 01 & & & 02 & \\
\hline & 25 & 052 & 1,0042 & 1,00 & 1,0023 & 1,0016 & 1,00 & 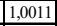 & 7 & 1,0 & 1,0 & & 1,0007 & & & & & & & & 3 & \\
\hline & 40 & 0009 & 1,0005 & 1,0005 & 0,9998 & 0,9995 & 0,9994 & 0,9994 & 1,0008 & 1,0004 & 1,0008 & & 0,9995 & 0,9995 & 0,9994 & & & 0,9993 & 96 & 991 & 995 & \\
\hline & 45 & 0019 & 1,0015 & 1,0014 & 1,0007 & 1,0003 & 1,0002 & 1,0001 & 1,0014 & 1,0010 & 1,0013 & 1,0 & 1,0001 & 1,0000 & & 1,0002 & 1,0000 & 97 & 1,0001 & 995 & & \\
\hline & $\mathbf{5 0}$ & 1,0005 & 1,0002 & 1,0003 & 0,9997 & 0,9994 & 0,9994 & 0,9994 & 1,0006 & 1,0003 & 1,0006 & 1,0004 & 0,9995 & 0,9994 & 0,9994 & 0,9997 & 0,9995 & 0,9993 & 0,9996 & 91 & 0,9 & 1,0 \\
\hline & 55 & 0013 & 1,0010 & 1,0010 & 1,0004 & 1,0001 & 1,0000 & 1,0000 & 1,0011 & 1,0008 & 1,00 & 1,0 & 0,9999 & 0,9999 & 0,9998 & 1,0001 & 0,9999 & 0,9997 & 1,0000 & 95 & 0,9998 & 1,0 \\
\hline & 60 & 6 & 1,0013 & 1,0013 & 1,0007 & 1,0004 & 1,0003 & 1,0002 & 1,0013 & 1,0 & 1,0 & 1,0 & 1,0001 & 1,0001 & 1,0000 & 1,0 & 1,0000 & 0,9 & 1,0 & 0, & 1,0 & \\
\hline & 65 & & 1,0013 & 1,0013 & 1,0008 & 1,0005 & 1,0003 & 1,0003 & 1,0 & 1,0 & 1,0 & 1,0 & 1,0002 & 1,0 & & & & 0,9999 & 1,0 & & 1,0 & \\
\hline & 90 & 0007 & 1,0005 & 1,0005 & 1,0002 & 1,0000 & 0,9999 & 0,9999 & 1,0007 & 1,0005 & 1,0007 & 1,0 & 0,9999 & 0,9998 & 0,9998 & 1,0000 & 0,9998 & 0,9996 & 0,9999 & 0,9995 & 0,9998 & 1,0002 \\
\hline & 95 & 0000 & 0,9999 & 0,9999 & 0,9996 & 0,9995 & 0,9994 & 0,9994 & 1,0002 & 1,0000 & 1,0002 & 1,0 & 9995 & ,9994 & 0,9994 & 9,9997 & 0,9995 & 0,9993 & , & & 0,9995 & 0,99 \\
\hline & 100 & 1,0011 & 1,0009 & 1,0009 & 1,0006 & 1,0004 & 1,0003 & 1,0003 & 1,0010 & 1,0008 & 1,0010 & 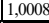 & 1,0002 & 1,0002 & 1,0001 & 1,0003 & 1,0001 & 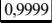 & 1,0002 & 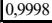 & 1,0000 & 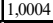 \\
\hline
\end{tabular}

Fonte: dados da Pesquisa 


\subsection{Detecção do desvio e início do processo de ajuste}

Para a quarta etapa, primeiramente é necessário localizar na matriz de janelas o maior retorno, que na exemplificação da ação Vale ON na Tabela 1, observa-se que o maior retorno se encontra na janela (5-2) [5 antes e 2 depois), com o valor de 1,0175. Tal janela representa o desvio devido ao evento e o início do subsequente processo de ajuste, que é designada como Janela B. A Figura 2 ilustra a sua identificação.

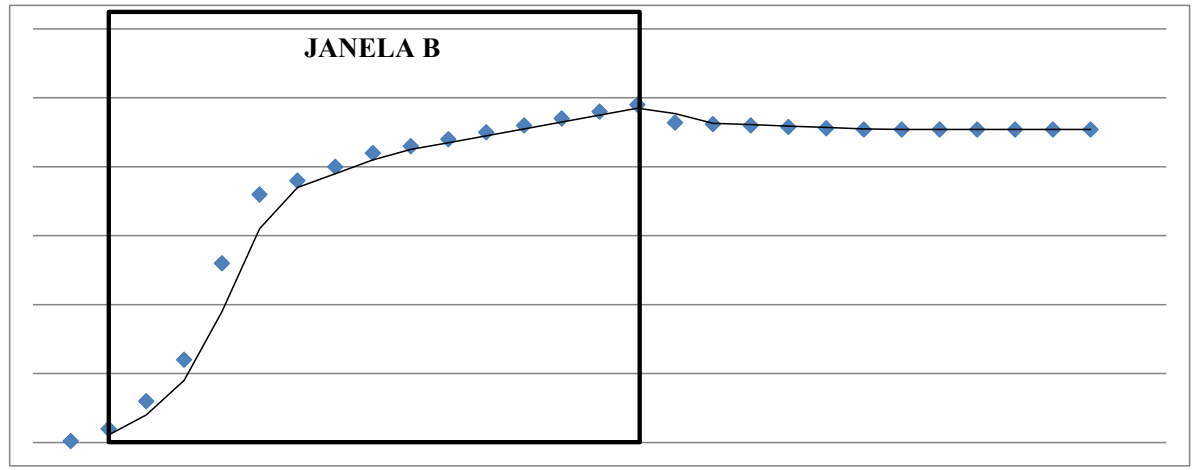

Figura 2 - Janela B - Desvio e processo de ajuste Fonte: dados da Pesquisa

\subsubsection{Detecção do salto devido ao evento}

A próxima etapa da metodologia é a detecção do saldo devido ao evento estudado. Neste sentido, a primeira fase da Janela B vista anteriormente apresenta aumento acelerado, devido ao desenvolvimento imediato dos efeitos do evento, e é designada por Janela A, conforme Figura 3. 


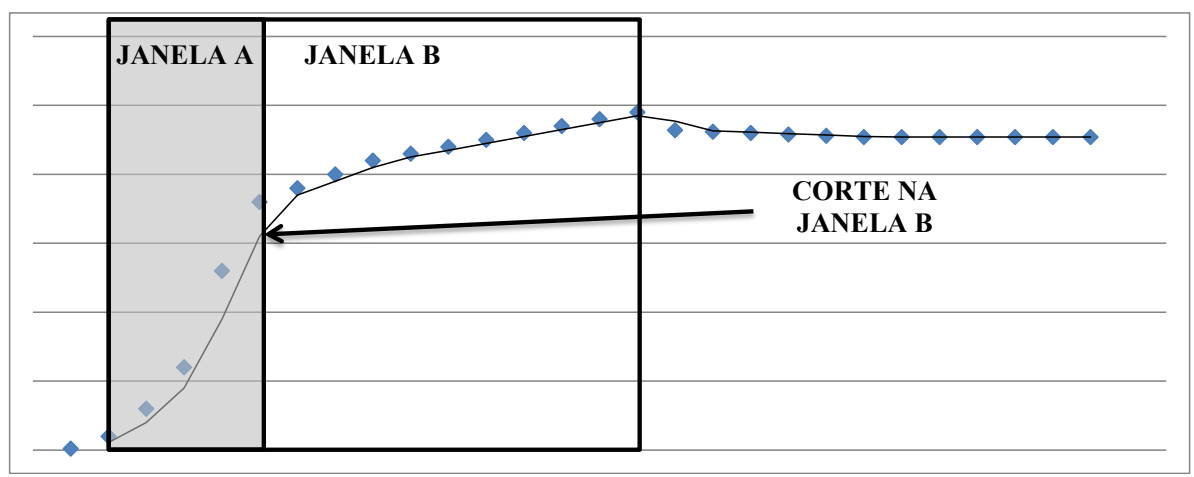

Figura 3 - Janela A - Salto devido ao evento

Fonte: dados da Pesquisa

De acordo com o exposto, torna-se necessário determinar o corte na Janela B, que para isso, primeiramente é fixada a coluna de maior valor encontrada na matriz, que no exemplo da Tabela 1, para a Vale ON, tem-se a coluna 2 com valor de 1,0175. Com tal fixação, aplica-se a Equação (5).

Diferença do Retorno Janela $A_{i j w}=$ Retorno Equiv ${ }_{i j w}-$ Retorno Equiv $_{\mathrm{ij}-1 \mathrm{w}}$

Em que,

Diferença Retorno Janela $\mathrm{A}_{\mathrm{ijw}}$ : diferença do retorno da Janela A do ativo i na posição j da coluna w;

Retorno Equiv $_{\mathrm{ijw}}$ : retorno equivalente do ativo i na posição j da coluna w;

Retorno Equiv $_{\mathrm{ijw} w-1 w}$ : retorno equivalente do ativo i na posição (j - 1) da coluna w;

Com a aplicação da Equação (5) torna-se possível verificar, para cada coluna 2, a maior diferença entre os retornos, a fim de estabelecer o corte na Janela B. Com a aplicação da Equação (5) à Tabela 1, obtêm-se os resultados expostos na Tabela 2. Na posição 2, o retorno da posição anterior () corresponde à data do evento, e que, portanto, de acordo com a Equação (3), apresenta retorno diferencial igual a 1. 
Tabela 2 - Janela A - VALE ON

\begin{tabular}{|c|c|c|c|c|c|c|c|c|c|c|c|c|c|c|c|c|c|c|c|c|c|c|}
\hline \multirow{2}{*}{\multicolumn{2}{|c|}{ JANELAS }} & \multicolumn{21}{|c|}{ DEPOIS } \\
\hline & & 2 & 5 & 10 & 15 & 20 & 25 & 30 & 35 & 40 & 45 & 50 & 55 & 60 & 65 & 70 & 75 & 80 & 85 & 90 & 95 & 100 \\
\hline \multirow{14}{*}{$\begin{array}{l}\text { 国 } \\
\frac{6}{2}\end{array}$} & 2 & 0,0127 & & & & & & & & & & & & & & & & & & & & \\
\hline & 5 & 0,0048 & & & & & & & & & & & & & & & & & & & & \\
\hline & 15 & $-0,0048$ & & & & & & & & & & & & & & & & & & & & \\
\hline & 20 & $-0,0048$ & & & & & & & & & & & & & & & & & & & & \\
\hline & 25 & $-0,0009$ & & & & & & & & & & & & & & & & & & & & \\
\hline & 40 & $-0,0019$ & & & & & & & & & & & & & & & & & & & & \\
\hline & 45 & 0,0010 & & & & & & & & & & & & & & & & & & & & \\
\hline & 50 & $-0,0013$ & & & & & & & & & & & & & & & & & & & & \\
\hline & 55 & 0,0008 & & & & & & & & & & & & & & & & & & & & \\
\hline & 60 & 0,0002 & & & & & & & & & & & & & & & & & & & & \\
\hline & 85 & $-0,0006$ & & & & & & & & & & & & & & & & & & & & \\
\hline & 90 & 0,0008 & & & & & & & & & & & & & & & & & & & & \\
\hline & 95 & $-0,0007$ & & & & & & & & & & & & & & & & & & & & \\
\hline & 100 & 0,0011 & & & & & & & & & & & & & & & & & & & & \\
\hline
\end{tabular}

Fonte: dados da Pesquisa

De acordo com a Tabela 2, pode-se observar que o corte na Janela B deve corresponder ao maior valor na coluna fixada, que é 0,0127. Desta forma, resumidamente, primeiramente é encontrada a Janela B, que no exemplo é (5-2). Na sequência, busca-se estabelecer o corte na Janela B, na posição 2 obtida. Com isso, conclui-se que a janela do evento da VALE ON é 2-2 (dois pregões antes e dois depois), quando se consideram 100 pregões antes e 100 pregões depois.

\subsubsection{Verificação das Janelas com redução de intervalos}

A partir da Tabela 1, devem ser definidas adequadamente submatrizes para números menores de pregões. Neste sentido, na Tabela 3 tem-se o exemplo da matriz com 90 pregões antes e depois para o mesmo caso exemplificado, VALE ON. 
Tabela 3 - Matriz de janelas para evento da ação VALE ON - 90 pregões antes e 90 depois

\begin{tabular}{|c|c|c|c|c|c|c|c|c|c|c|c|c|c|c|c|c|c|c|c|c|c|c|}
\hline \multirow{2}{*}{\multicolumn{2}{|c|}{ JANELAS }} & \multicolumn{21}{|c|}{ DEPOIS } \\
\hline & & 2 & 5 & 10 & 15 & 20 & 25 & 30 & 35 & 40 & 45 & 50 & 55 & 60 & 65 & 70 & 75 & 80 & 85 & 90 & & \\
\hline \multirow{21}{*}{ 聓 } & 2 & 1,0127 & 1,0051 & 1,0034 & 1,0003 & 0,9993 & \begin{tabular}{|l}
0,9991 \\
\end{tabular} & 0,9992 & 1,0020 & 1,0011 & 1,0017 & 1,0012 & 0,9994 & \begin{tabular}{|l|}
0,9994 \\
\end{tabular} & \begin{tabular}{|l|}
0,9993 \\
\end{tabular} & 0,9999 & 0,9995 & 0,9991 & 0,9997 & 0,9989 & & \\
\hline & 5 & 1,0175 & 1,0108 & 1,0075 & 1,0038 & 1,0022 & 1,0016 & 1,0013 & 1,0036 & 1,0026 & 1,0030 & 1,0024 & 1,0007 & 1,0005 & 1,0004 & 1,0008 & \begin{tabular}{|l|l|}
1,004 \\
\end{tabular} & 1,0000 & 1,0005 & 0,9996 & & \\
\hline & 10 & 1,0156 & 1,0115 & \begin{tabular}{|l|}
1,0088 \\
\end{tabular} & \begin{tabular}{|l|l|}
1,006 \\
\end{tabular} & 1,0040 & 1,0032 & 1,0027 & 1,0047 & \begin{tabular}{|l|l|}
1,0037 \\
\end{tabular} & 1,0039 & \begin{tabular}{|l|}
1,0033 \\
\end{tabular} & \begin{tabular}{|l|}
1,0016 \\
\end{tabular} & 1,0014 & \begin{tabular}{|l|}
1,0012 \\
\end{tabular} & 1,0016 & \begin{tabular}{|l|l|} 
\\
\end{tabular} & \begin{tabular}{|l|}
1,0007 \\
\end{tabular} & 1,0011 & 1,0003 & & \\
\hline & 15 & 1,0109 & 1,0085 & 1,0070 & 1,0046 & 1,0034 & 1,0027 & 1,0024 & 1,0041 & 1,0033 & 1,0036 & 1,0030 & 1,0014 & 1,0013 & 1,0011 & 1,0015 & 1,0010 & 1,0006 & 1,0010 & 1,0003 & & \\
\hline & 20 & 1,0060 & 1,0047 & 1,0041 & 1,0025 & 1,0017 & 1,0013 & 1,0011 & 1,0028 & 1,0022 & 1,0025 & 1,0020 & $\mid 1,0007$ & 1,0006 & 1,0004 & 1,0008 & 1,0004 & \begin{tabular}{|l|}
1,0001 \\
\end{tabular} & 1,0005 & 0,9998 & & \\
\hline & 25 & 1,0052 & 1,0042 & 1,0037 & 1,0023 & 1,0016 & 1,0013 & 1,0011 & 1,0027 & \begin{tabular}{|l|}
1,0021 \\
\end{tabular} & 1,0024 & 1,0020 & \begin{tabular}{|l|}
1,0007 \\
\end{tabular} & 1,0006 & \begin{tabular}{|l|}
1,0005 \\
\end{tabular} & 1,0008 & \begin{tabular}{|l|l|}
1,005 \\
\end{tabular} & \begin{tabular}{|l|l|}
1,002 \\
\end{tabular} & 1,0005 & 0,9999 & & \\
\hline & 30 & 1,0020 & 1,0014 & 1,0013 & 1,0004 & 0,9999 & 0,9998 & 0,9998 & 1,0013 & \begin{tabular}{|l|}
1,0009 \\
\end{tabular} & 1,0012 & 1,0009 & \begin{tabular}{|l|}
0,9998 \\
\end{tabular} & 0,9997 & \begin{tabular}{|l|}
0,9997 \\
\end{tabular} & 1,0000 & 0,9997 & 0,9995 & 0,9998 & 0,9992 & & \\
\hline & 35 & 1,0027 & 1,0022 & 1,0020 & 1,0011 & 1,0006 & 1,0004 & 1,0004 & 1,0018 & 1,0013 & 1,0016 & \begin{tabular}{|l|}
1,0013 \\
\end{tabular} & 1,0002 & 1,0001 & 1,0000 & 1,0004 & 1,0001 & $\mid 0,9998$ & 1,0002 & 0,9996 & & \\
\hline & 40 & 1,0009 & 1,0005 & 1,0005 & 0,9998 & 0,9995 & 0,9994 & 0,9994 & 1,0008 & 1,0004 & 1,0008 & 1,0005 & 0,9995 & 0,9995 & \begin{tabular}{|l|l|} 
\\
\end{tabular} & 0,9998 & 0,9995 & \begin{tabular}{|l|}
0,9993 \\
\end{tabular} & 0,9996 & 0,9991 & & \\
\hline & 45 & 1,0019 & 1,0015 & 1,0014 & 1,0007 & 1,0003 & 1,0002 & 1,0001 & 1,0014 & 1,0010 & 1,0013 & 1,0010 & 1,0001 & 1,0000 & 0,9999 & 1,0002 & 1,0000 & 0,9997 & 1,0001 & 0,9995 & & \\
\hline & 50 & 1,0005 & 1,0002 & \begin{tabular}{|l|}
1,0003 \\
\end{tabular} & \begin{tabular}{|l|}
0,9997 \\
\end{tabular} & 0,9994 & 0,9994 & 0,9994 & 1,0006 & \begin{tabular}{|l|}
1,0003 \\
\end{tabular} & 1,0006 & \begin{tabular}{|l|}
1,0004 \\
\end{tabular} & \begin{tabular}{|l|}
0,9995 \\
\end{tabular} & 0,9994 & \begin{tabular}{|l|}
0,9994 \\
\end{tabular} & \begin{tabular}{|l|l|}
0,9997 \\
\end{tabular} & \begin{tabular}{|l|}
0,9995 \\
\end{tabular} & \begin{tabular}{|l|}
0,9993 \\
\end{tabular} & 0,9996 & 0,9991 & & \\
\hline & 55 & 1,0013 & 1,0010 & \begin{tabular}{|l|}
1,0010 \\
\end{tabular} & \begin{tabular}{|l|l}
1,0004 \\
\end{tabular} & 1,0001 & 1,0000 & 1,0000 & 1,0011 & \begin{tabular}{|l|}
1,0008 \\
\end{tabular} & 1,0011 & 1,0008 & \begin{tabular}{|l|}
0,9999 \\
\end{tabular} & 0,9999 & \begin{tabular}{|l|}
0,9998 \\
\end{tabular} & 1,0001 & \begin{tabular}{|l|}
0,9999 \\
\end{tabular} & \begin{tabular}{|l|}
0,9997 \\
\end{tabular} & 1,0000 & 0,9995 & & \\
\hline & 60 & 1,0016 & 1,0013 & \begin{tabular}{|l|}
1,0013 \\
\end{tabular} & \begin{tabular}{|l|}
1,0007 \\
\end{tabular} & 1,0004 & 1,0003 & 1,0002 & 1,0013 & \begin{tabular}{|l|l|} 
\\
\end{tabular} & 1,0012 & 1,0010 & \begin{tabular}{|l|l|} 
\\
\end{tabular} & 1,0001 & 1,0000 & 1,0003 & 1,0000 & \begin{tabular}{|l|}
0,9998 \\
\end{tabular} & 1,0001 & 0,9996 & & \\
\hline & 65 & 1,0016 & 1,0013 & \begin{tabular}{|l|}
1,0013 \\
\end{tabular} & 1,0008 & 1,0005 & 1,0003 & 1,0003 & 1,0013 & 1,0010 & 1,0012 & 1,0010 & 1,0002 & 1,0001 & \begin{tabular}{|l|}
1,0001 \\
\end{tabular} & 1,0003 & \begin{tabular}{|l|l|} 
\\
\end{tabular} & \begin{tabular}{|l|}
0,9999 \\
\end{tabular} & 1,0002 & 0,9997 & & \\
\hline & 70 & 1,0011 & 1,0009 & 1,0009 & 1,0004 & 1,0002 & 1,0001 & 1,0000 & 1,0010 & 1,0007 & 1,0010 & 1,0008 & 1,0000 & 1,0000 & \begin{tabular}{|l|}
0,9999 \\
\end{tabular} & 1,0002 & \begin{tabular}{|l|}
0,9999 \\
\end{tabular} & 0,9997 & 1,0000 & 0,9995 & & \\
\hline & 75 & 1,0008 & 1,0006 & 1,0006 & 1,0002 & 1,0000 & 0,9999 & 0,9999 & 1,0008 & 1,0005 & 1,0008 & 1,0006 & 0,9999 & 0,9998 & \begin{tabular}{|l|}
0,9998 \\
\end{tabular} & 1,0000 & \begin{tabular}{|l|l|} 
\\
\end{tabular} & 0,9996 & 0,9999 & 0,9994 & & \\
\hline & 80 & 1,0006 & 1,0004 & 1,0004 & 1,0000 & 0,9998 & \begin{tabular}{|l}
0,9997 \\
\end{tabular} & 0,9997 & 1,0006 & 1,0004 & 1,0006 & 1,0004 & 0,9997 & 0,9997 & \begin{tabular}{|l|}
0,9997 \\
\end{tabular} & 0,9999 & 0,9997 & 0,9995 & 0,9998 & 0,9993 & & \\
\hline & 85 & 0,9999 & 0,9998 & \begin{tabular}{|l|}
0,9998 \\
\end{tabular} & 0,9995 & 0,9993 & 0,9993 & 0,9993 & 1,0001 & \begin{tabular}{|l|l}
0,9999 \\
\end{tabular} & 1,0002 & 1,0000 & \begin{tabular}{|l|l}
0,9994 \\
\end{tabular} & \begin{tabular}{|l|}
0,9993 \\
\end{tabular} & \begin{tabular}{|l|}
0,9993 \\
\end{tabular} & 0,9996 & \begin{tabular}{|l|l}
0,9994 \\
\end{tabular} & \begin{tabular}{|l|l}
0,9992 \\
\end{tabular} & 0,9995 & 0,9991 & & \\
\hline & 90 & 1,0007 & 1,0005 & \begin{tabular}{|l|}
1,0005 \\
\end{tabular} & 1,0002 & 1,0000 & 0,9999 & 0,9999 & 1,0007 & 1,0005 & 1,0007 & \begin{tabular}{|l|}
1,0005 \\
\end{tabular} & 0,9999 & \begin{tabular}{|l|}
0,9998 \\
\end{tabular} & \begin{tabular}{|l|}
0,9998 \\
\end{tabular} & 1,0000 & 0,9998 & \begin{tabular}{|l|}
0,9996 \\
\end{tabular} & 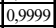 & 0,9995 & & \\
\hline & & & & & & & & & & & & & & & & & & & & & & \\
\hline & & & & & & & & & & & & & & & & & & & & & & \\
\hline
\end{tabular}

Fonte: dados da Pesquisa

Com a redução dos intervalos, para todos os casos estudados foram utilizadas as seguintes matrizes (pregões antes e depois): 100-100, 90-90, 80-80, 70-70, 60-60, 50-50, 40-40, 30-30, 20-20, 15-15, 10-10, 5-5. Desta forma, foram detectadas a Janela B, a Janela A e o corte da Janela B para todas as submatrizes representativas de intervalos reduzidos.

Finalmente, para cada elemento da amostra foi obtida a melhor janela do evento para todos os intervalos estudados. Na Tabela 4 mostram-se as janelas de eventos encontradas para o evento da VALE ON.

Tabela 4 - Janela do evento para a ação VALE ON

\begin{tabular}{c|c|c|c|}
\hline Submatrizes & Início & Fim & Janelas \\
\hline $\mathbf{1 0 0 / 1 0 0}$ & 2 & 2 & $2-2$ \\
\hline $\mathbf{9 0 / 9 0}$ & 2 & 2 & $2-2$ \\
\hline $\mathbf{8 0 / 8 0}$ & 2 & 2 & $2-2$ \\
\hline $\mathbf{7 0} / \mathbf{7 0}$ & 2 & 2 & $2-2$ \\
\hline $\mathbf{6 0 / 6 0}$ & 2 & 2 & $2-2$ \\
\hline $\mathbf{5 0} / \mathbf{5 0}$ & 2 & 2 & $2-2$ \\
\hline $\mathbf{4 0 / 4 0}$ & 2 & 2 & $2-2$ \\
\hline $\mathbf{3 0 / 3 0}$ & 2 & 2 & $2-2$ \\
\hline $\mathbf{2 0} / \mathbf{2 0}$ & 2 & 2 & $2-2$ \\
\hline $\mathbf{1 5} / \mathbf{1 5}$ & 2 & 2 & $2-2$ \\
\hline $\mathbf{1 0} / \mathbf{1 0}$ & 2 & 2 & $2-2$ \\
\hline $\mathbf{5 / 5}$ & 2 & 2 & $2-2$ \\
\hline
\end{tabular}

Fonte: dados da Pesquisa 
Observa-se que para todas as variações de submatrizes a janela 2-2 sempre se apresentou como a que melhor capta os efeitos do evento de interesse. Com isso, na análise dos resultados expostos a seguir é utilizado o conceito de pregão mais representativo. Tanto para a análise anterior como posterior ao evento, o pregão mais representativo é o intervalo de tempo em referência à data do evento que evidencia maior diferença entre os retornos estudados. 